Published in final edited form as:

Nat Rev Drug Discov. 2014 April ; 13(4): 290-314. doi:10.1038/nrd4228.

\title{
Advances in targeting cyclic nucleotide phosphodiesterases
}

\author{
Donald H. Maurice ${ }^{1}$, Hengming $\mathrm{Ke}^{2}$, Faiyaz Ahmad ${ }^{3}$, Yousheng Wang ${ }^{4}$, Jay Chung $^{5}$, and \\ Vincent C. Manganiello 3 \\ 1Biomedical and Molecular Sciences, Queen's University, Kingston K7L3N6, Ontario, Canada \\ ${ }^{2}$ Lineberger Comprehensive Cancer Center, University of North Carolina, Chapel Hill, North \\ Carolina 27599, USA
}

${ }^{3}$ Cardiovascular and Pulmonary Branch, The National Heart, Lung and Blood Institute, US National Institutes of Health, Bethesda, Maryland 20892, USA

${ }^{4}$ Beijing Technology and Business University, Beijing 100048, China

${ }^{5}$ Genetics and Developmental Biology Center, The National Heart, Lung and Blood Institute, US National Institutes of Health, Bethesda, Maryland 20892, USA

\begin{abstract}
Cyclic nucleotide phosphodiesterases (PDEs) catalyse the hydrolysis of cyclic AMP and cyclic GMP, thereby regulating the intracellular concentrations of these cyclic nucleotides, their signalling pathways and, consequently, myriad biological responses in health and disease. Currently, a small number of PDE inhibitors are used clinically for treating the pathophysiological dysregulation of cyclic nucleotide signalling in several disorders, including erectile dysfunction, pulmonary hypertension, acute refractory cardiac failure, intermittent claudication and chronic obstructive pulmonary disease. However, pharmaceutical interest in PDEs has been reignited by the increasing understanding of the roles of individual PDEs in regulating the subcellular compartmentalization of specific cyclic nucleotide signalling pathways, by the structure-based design of novel specific inhibitors and by the development of more sophisticated strategies to target individual PDE variants.
\end{abstract}

Efficient integration of myriad extracellular and intracellular signals is required to maintain adaptive cellular functioning. Dysregulation of this integration promotes maladaptive cellular functions and underpins human diseases. Numerous distinct cellular signal transduction systems have evolved to allow cells to receive these various inputs, to translate

(C) 2014 Macmillan Publishers Limited. All rights reserved

Correspondence to V.C.M. manganiv@nhlbi.nih.gov.

Competing interests statement

The authors declare no competing interests.

DATABASES

ClinicalTrials.gov website: http://www.clinicaltrials.gov/

Protein Data Bank: http://www.rcsb.org/

SUPPLEMENTARY INFORMATION

See online article: $S 1$ (figure) | S2 (figure) | S3 (table)

ALL LINKS ARE ACTIVE IN THE ONLINE PDF 
their codes and, subsequently, to transduce and integrate their meanings. Two of these, the cAMP and the cGMP signalling systems (sometimes together referred to as the cyclic nucleotide signalling system), are among the earliest identified signal transduction systems. Advances in our understanding of the mechanisms by which cellular functions are altered through cyclic nucleotide signalling are enabling the identification and development of therapeutic agents for use in numerous human diseases.

The cAMP- and cGMP-signalling systems regulate a vast number of physiological processes, including visual transduction, cell proliferation and differentiation, gene expression, inflammation, apoptosis and metabolic pathways such as steroidogenesis, insulin secretion and glycogen synthesis, as well as glycogenolysis, lipogenesis and lipolysis ${ }^{1-3}$. Once synthesized by adenylyl cyclases or guanylyl cyclases, respectively, cAMP and cGMP transduce signal-encoded information by acting through a number of cellular effectors. These include cAMP- or cGMP-activated protein kinases (protein kinase A (PKA) or PKG, respectively), cyclic nucleotide-gated ion channels, a family of two cAMP-activated guanine nucleotide exchange proteins (exchange factors directly activated by cAMP 1 (EPAC1) and EPAC2) and a limited group of enzymes from the cyclic nucleotide phosphodiesterase (PDE) family, which contain allosteric cyclic nucleotide-binding sites in addition to their catalytic sites $^{1-3}$. Because the activities of several of these effectors can be altered simultaneously in response to increases in cellular cAMP or cGMP, cyclic nucleotideelevating agents can trigger multiple cellular signalling events that - when integrated yield a series of finely-tuned 'read-outs' and that markedly affect the numerous cellular functions listed above.

The functional impact and therapeutic utility of agents that increase the synthesis of either cAMP or cGMP have been established ${ }^{4-7}$. Indeed, agents that are designed to act by binding to and activating selected $\mathrm{G}$ protein-coupled receptors (GPCRs), including drugs such as salmeterol (for asthma) ${ }^{7}$ or exendin- 4 (for diabetes) ${ }^{8}$, affect cellular functions by stimulating adenylyl cyclases. Similarly, agents that promote guanylyl cyclase-catalysed synthesis of cGMP have therapeutic utility; these include nitric oxide donor drugs such as glyceryl trinitrate (for angina therapy) $)^{9}$ or the natriuretic peptide-inspired drugs ${ }^{10}$ such as nesiritide, a recombinant form of human B-type natriuretic peptide (BNP).

The functional impact and therapeutic utility of blocking cyclic nucleotide hydrolysis catalysed by cyclic nucleotide PDEs have also long been recognized. Indeed, shortly after discovering that cAMP was the heat-stable factor responsible for the activation of hepatic glycogen phosphorylase by adrenaline, Sutherland and colleagues ${ }^{11}$ identified the enzymatic activity of PDE as the cellular activity responsible for the hydrolysis of the $3^{\prime}, 5^{\prime}$ phosphodiester bond of cAMP to yield 5'-AMP, and they identified caffeine as an inhibitor of this activity. Furthermore, caffeine, along with theophylline, was shown to potentiate the cAMP-increasing effects of adrenaline as well as the ability of adrenaline to activate phosphorylase or stimulate inotropic responses in perfused hearts ${ }^{12}$.

These early findings highlighted the importance of PDEs as essential regulators of intracellular cyclic nucleotide concentrations and their biological effects. The subsequent years have seen the confirmation of the crucial roles of PDEs as regulators of intracellular 
cyclic nucleotide concentrations, as well as the discovery of a host of biological processes involving these second messengers in health and disease ${ }^{1-3}$. For these reasons, and others detailed in this Review, PDEs have consistently been considered to be key therapeutic targets, from both clinical and economic perspectives.

Nevertheless, at present only a few PDE inhibitors are in widespread clinical use. However, recent advances have renewed enthusiasm for further investigating their therapeutic potential. First, individual PDEs have been shown to control select cyclic nucleotideregulated events by their integration into specific multi-molecular regulatory signalling complexes, termed 'signalosomes', and through their regulation of cAMP or cGMP levels within distinct and largely non-overlapping intracellular cyclic nucleotide compartments ${ }^{13,14}$. Indeed, there is evidence to suggest that the disruption of these signalling modules and the resultant dysregulation of this compartment-specific signalling via genetic, epigenetic or cellular environmental influences may be associated with many disease states, including asthma, inflammation, erectile dysfunction, hypertension, heart failure and cardiac arrhythmias ${ }^{1-3,13,14}$.

Furthermore, it has been suggested that targeting these compartments could yield greater therapeutic specificity. There is growing confidence that this will be possible, given the recent remarkable advances in PDE biology and structural biology, including structurefunction studies, advanced proteomics, X-ray crystallographic analysis of PDEs ${ }^{15}$ and PDEinhibitor complexes ${ }^{16,17}$, as well as the development of more sophisticated strategies to examine the unique allosteric interactions between the catalytic and regulatory domains of PDEs $^{18}$ and to target specific PDEs in complex with their signalosome partners ${ }^{19}$. These advances may enable the development of effective therapies for a broad range of clinical applications, including asthma, inflammation, depression, stroke, schizophrenia, chronic cardiac failure and atherosclerosis. This Review focuses on these recent advances, as well as on translational research in the PDE field.

\section{History of PDEs as therapeutic targets}

Xanthine derivatives, including theophylline and caffeine, were clinically used as bronchodilators (for the treatment of asthma), diuretics and inotropic agents before they were identified as non-selective PDE inhibitors ${ }^{20,21}$. However, their unfavourable riskbenefit ratio and side-effect profiles considerably impeded their therapeutic success. In the 1970s and 1980s, simple gel filtration and ion exchange chromatography of tissue extracts revealed multiple peaks of PDE activities, with each peak exhibiting different specificities and affinities for cGMP and/or cAMP as well as different sensitivities to available pharmacological agents and effectors such as calcium/calmodulin (the calcium/calmodulinsensitive PDE is now known as PDE1) ${ }^{22-26}$. Consequently, drugs were successfully utilized to subdivide cAMP-hydrolysing PDEs into cilostamide-sensitive (now known as PDE3) and Ro20-1724-sensitive (now known as PDE4) enzymes ${ }^{27}$. Responsiveness to cGMP was also used to identify distinct PDEs: that is, cGMP-inhibited cAMP-hydrolysing PDEs (now known as PDE3) ${ }^{25}$, cGMP-stimulated cAMP-hydrolysing PDEs (now known as PDE2) ${ }^{27}$ and cGMP-specific PDEs (now known as PDE5) ${ }^{26}$. 
Thus, molecular diversity among PDEs was recognized long before modern molecular biology and molecular genetics revealed the large number and complexity of PDEs, and before the current organization of the large mammalian PDE superfamily into 11 structurally related but functionally distinct PDE gene families (PDE1 to PDE11) ${ }^{1-3}$ (FIG. 1). The recognition that the molecular diversity of PDEs is coupled to the regulation of specific and functionally important physiological and pathophysiological processes (TABLES 1,2) has spurred the pharmaceutical industry to develop specific second-generation inhibitors that are selective for 9 of the 11 PDE families (TABLE 2).

In the 1980s, PDE3 and PDE4 were the primary therapeutic targets. As PDE3 inhibitors were discovered to exhibit cardiotonic, inotropic, bronchodilatory and vasodilatory activities in several species, they were developed as cardiotonic agents to replace or add to cardiac glycosides in the treatment of cardiac failure ${ }^{20,28}$. PDE4 inhibitors have antidepressive and anti-inflammatory activities, but were initially developed to treat chronic obstructive pulmonary disease (COPD) and asthma ${ }^{20,29,30}$. Unfortunately, the hopes that arose from preclinical studies were not completely realized in clinical trials, and many of these early second-generation PDE3 and PDE4 inhibitors were not approved owing to lack of efficacy and the presence of intolerable side effects ${ }^{20,28,31}$.

As discussed below and listed in TABLE 2, other second-generation inhibitors of PDE3 and PDE4, with more favourable risk-benefit profiles, are now available $20,30-32$ and hold promise for use in additional disease states. During early unsuccessful clinical trials assessing the potential of the PDE5 inhibitor sildenafil (Viagra; Pfizer) in the treatment of angina and coronary artery disease, responses in off-target tissues dramatically changed the focus of this agent to erectile dysfunction. The enormous success of PDE5 inhibitors in treating erectile dysfunction ${ }^{33}$ and, more recently, pulmonary hypertension ${ }^{34}$ has been a major contributing factor in maintaining and expanding pharmaceutical interest in PDEs as promising therapeutic targets for many diseases (TABLE 2).

\section{Overview of the PDEs}

\section{Structural organization}

The 11 structurally related but functionally distinct gene families (PDE1 to PDE11) that comprise the PDE superfamily differ in their cellular functions, primary structures, affinities for cAMP and cGMP, catalytic properties and responses to specific activators, inhibitors and effectors, as well as in their mechanisms of regulation ${ }^{1-3}$ (FIG. 1; TABLES 1,2). Most families contain several PDE genes (for example, PDE1A, PDE1B and PDE1C (FIG. 1; TABLE 1)), which together generate close to $100 \mathrm{PDE}$ isozymes by alternative mRNA splicing or transcriptional processing.

As modular proteins, PDEs exhibit a common structural organization, with divergent aminoterminal regulatory regions (FIG. 1) and a conserved carboxy-terminal catalytic core. Some PDEs specifically hydrolyse cAMP (PDE4, PDE7 and PDE8), whereas others specifically hydrolyse cGMP (PDE5, PDE6 and PDE9), and some hydrolyse both (PDE1, PDE2, PDE3, PDE10 and PDE11 $)^{1-3}$. The N-terminal regulatory regions of PDEs contain structural determinants that target individual PDEs to different sub-cellular locations and 
signalosomes ${ }^{13,14,19}$, and also allow individual PDEs to specifically respond to different post-translational modifications, regulatory molecules and signals. These structural elements include dimerization domains, autoinhibitory modules, binding sites for ligands and allosteric effectors, phosphorylation sites and other covalent modification sites, domains for isoform-specific protein-protein interactions with specific scaffolds and regulatory partners, and so on (FIG. 1).

Most cells contain representatives of more than one PDE family, but in varying amounts, proportions and subcellular locations. Although PDEs exhibit a broad tissue distribution (TABLE 1), some cells are relatively enriched in specific PDEs; for example, the photoreceptor PDE6 is almost exclusively expressed in retinal rods and cones ${ }^{3}$.

\section{Architecture of the catalytic core of PDEs: implications for the design of inhibitors}

$\mathrm{X}$-ray crystal structures of isolated catalytic domains of nine PDE families (PDE1-PDE5 and PDE7-PDE10) $)^{15}$, of the near-full-length PDE2A ${ }^{18}$ and of PDE4 catalytic domains with a fragment of upstream conserved regions (UCRs) ${ }^{35}$ have demonstrated that the catalytic domains of PDEs share a similar topography, composed of $\sim 350$ amino acids folded into 16 helices. Across the PDE families, the active site forms a deep hydrophobic pocket that contains a PDE-specific, histidine-containing signature motif, $\operatorname{HD}\left(\mathrm{X}_{2}\right) \mathrm{H}\left(\mathrm{X}_{4}\right) \mathrm{N}$, and binding sites for two divalent metal ions that are essential for catalytic function ${ }^{36}$. Of the six invariant residues in the metal binding site, one (His160 in PDE4D2) has been proposed to serve as a general acid for catalysis ${ }^{15,37}$. The catalytic pocket is lined with highly conserved and invariant residues, including an invariant glutamine (Gln369 in PDE4D2, Gln453 in PDE9A2 and Gln726 in PDE10A2) that forms crucial hydrogen bonds with substrates (FIG. 2a,b) and inhibitors ${ }^{15,16,38,39}$ (FIG. 2c,d) (see also Supplementary information S1 (figure), part A; Supplementary information S2 (figure)).

Analyses of crystal structures of PDE-inhibitor complexes (FIG. 2c,d) (see also Supplementary information S1 (figure), part A; Supplementary information S2 (figure)) suggest that two conserved residues, the invariant glutamine and a highly conserved phenylalanine (Phe372 in PDE4D2; Trp621 in PDE11A2), are essential for inhibitor binding $15,16,36,40$. The formation of hydrogen bonds with the invariant glutamine determines the orientation of inhibitors, and conserved hydrophobic residues (Ile336 and Phe340 in PDE4D2) ${ }^{16,40}$ form a 'hydrophobic clamp' that anchors inhibitors in the pocket and wedges their ring structures against Phe372 in PDE4D2 (Supplementary information S1 (figure), part A) ${ }^{16,36,38,40}$ and against Phe456 and Phe729 in PDE9A and PDE10A, respectively (Supplementary information S2 (figure)) ${ }^{16,17,41-45}$.

In addition to conserved elements that are responsible for binding to cyclic nucleotides and inhibitors, the catalytic core contains variable determinants that regulate PDE familyspecific substrate and inhibitor affinities and selectivities ${ }^{3,17,46}$ (TABLE 2). Inhibitor selectivity for individual PDE families is regulated by these variable active site residues, which define not only the chemical nature of the interactions but also the slightly different sizes of the subpockets ${ }^{38,45,47}$. For example, the formation of a hydrogen bond between inhibitors and the variable Tyr424 residue of PDE9A, which is replaced by phenylalanine in other PDE families (except for PDE8), substantially improved the affinity and selectivity of 
PDE9 inhibitors ${ }^{43,44}$ (Supplementary information S2 (figure), parts A and B). In addition, most PDE families - that is, PDE1 to PDE4 and PDE7 to PDE10 - have relatively rigid pockets at the active sites, further constraining inhibitor structure with implications regarding binding specificity and family selectivity. This rigidity was demonstrated by the co-crystallization of two enantiomers of Merck's inhibitors L-869298 and L-869299 with PDE4D (Supplementary information S1 (figure), part B) ${ }^{48}$. L-869299 inhibits PDE4D 107fold more weakly than L-869298 (with a half-maximal inhibitory concentration $\left(\mathrm{IC}_{50}\right)$ of 43 $\mathrm{nM}$ versus $0.4 \mathrm{nM}$ ). As both enantiomers assumed similar conformations or orientations owing to the rigidity of the PDE4D catalytic pocket, this suggested that L-869299 was forced to bind in an unfavourable orientation (Supplementary information S1 (figure), part B).

The catalytic domain of PDE5, however, appears to be unique for its ability to adopt multiple conformations of its helical H-loop (residues 660-683) and M-loop (residues 788811) at the active site, upon binding to different inhibitors, including isobutyl-1methylxanthine (IBMX), sildenafil and vardenafil (Levitra; Bayer) (Supplementary information S1 (figure), parts C and D). Crystal structures showed that both the H- and Mloops of PDE5 exhibit different conformations when sildenafil and vardenafil bind, which may account for the values and is prob-5-20-fold differences in their $\mathrm{IC}_{50}$ ably related to their somewhat distinct core structures (Supplementary information S1 (figure), part D) ${ }^{49,50}$.

Although many of the family-selective inhibitors listed in TABLE 2 have been developed using classical medicinal chemistry approaches, a structure-based design approach is now the preferred path for generating novel inhibitors (BOX 1). Family-selective PDE inhibitors (TABLE 2) have served as essential basic research tools to help understand both the complexities of cyclic nucleotide signalling pathways and the different regulatory and functional roles of individual PDEs in intact cells (TABLE 2). Family-selective PDE inhibitors are also potential therapeutics for a broad range of diseases, with greater specificity and fewer side effects than the non-selective first-generation PDE inhibitors such as theophylline, caffeine and other xanthine derivatives (FIG. 1; TABLE 2).

\section{Box 1}

\section{Structure-based design of PDE inhibitors}

Many of the high-affinity, family-selective, competitive inhibitors listed in TABLE 2 were generated using classical medicinal chemistry approaches ${ }^{16,17}$. This strategy, which almost exclusively identified compounds that competed with the binding of cyclic nucleotide substrates at the catalytic sites of phosphodiesterases (PDEs), involved screening extensive molecular libraries to identify lead compounds with modest potency and selectivity. These lead compounds served as scaffolds for systematic derivatization and chemical modification or optimization to produce second-generation, familyselective, competitive inhibitors with desired affinities, selectivities, potencies and favourable pharmacokinetics and safety profiles.

More recently, however, information from crystal structures of the catalytic sites of PDEs and of PDE-inhibitor complexes is driving the design of new inhibitors $15,16,17,40,163$. 
Lead candidates (usually of low affinity) are identified by a combination of compound library screening and high-throughput co-crystallization of PDE-inhibitor complexes. More potent and selective inhibitors are then generated by an iterative process of cocrystallography, whereby compounds are identified by additional focused library screening and/or they are chemically synthesized after structure-informed virtual screening and computational design. This approach has resulted in the discovery of several novel pyrazole derivatives as potent and selective PDE4 inhibitors ${ }^{40,163}$, of pyrazolopyrimidinones (such as PF-04447943) as PDE9A inhibitors for cognitive disorders ${ }^{43,44}$, and of pyridopyrazo-loquinolines (such as PF-2545920) as PDE10A inhibitors for the treatment of schizophrenia ${ }^{41,42,45}$. In the latter case, the cocrystallization of lead scaffold triarylimidazole compounds (identified by highthroughput screening of the Pfizer compound library) with the catalytic fragment of PDE10A identified a unique, PDE10A-specific, hydrophobic selectivity pocket for PDE10A inhibitors. This structural information was crucial in the design and chemical synthesis of PF-2545920, a potent (with a half-maximal inhibitory concentration $\left(\mathrm{IC}_{50}\right)$ of $0.37 \mathrm{nM}$ ) and highly selective PDE10A inhibitor ${ }^{45}$.

\section{Compartmentalization and the signalosome concept}

Early studies, particularly those reporting data that were consistent with the novel idea that cellular cAMP signalling was compartmentalized ${ }^{51,52}$, were met with considerable resistance. Indeed, it was not until the purification of A-kinase anchor proteins (AKAPs) and their identification as selective subcellular PKA tethers ${ }^{53,54}$ that a potential mechanism for compartmentalized cAMP signalling was conceived. More recently, the use of several distinct types of cAMP biosensors, including those that utilize fluorescence resonance energy transfer (FRET), in combination with biochemical approaches, has confirmed that cells regulate their intracellular levels of cAMP or cGMP in a highly compartmentalized manner and generate functionally separate intracellular cyclic nucleotide pools ${ }^{55-60}$.

Briefly, compartmentalized cyclic nucleotide signalling is established via the formation of cyclic nucleotide signalosomes, in which unique combinations of cyclic nucleotide effectors (PKAs, EPACs, cyclic nucleotide-gated ion channels or PKGs) and individual — or subsets of - PDEs form specific complexes via protein-protein interactions with one another and/or with localized scaffolding proteins, such as AKAPs, $\beta$-arrestin or receptor of activated protein kinase C1 (RACK1) 13,14,61. Different AKAPs, for example, serve dual functions as tethers for PKA at different subcellular locations in close proximity to PKA substrates in order to promote selective phosphorylation, and as scaffolds for signalosomes with different proportions of PKA, adenylyl cyclases, other kinases, phosphatases, EPACs, PDEs and other effector molecules ${ }^{13,14,61}$. Thus, as components of specific signalosomes, PDEs modulate the diffusion and turnover of cyclic nucleotide gradients within spatially restricted and temporally regulated compartments, and they reduce the diffusion of cyclic nucleotide signals into neighbouring compartments. TABLE 3 and Supplementary information S3 (table) provide a comprehensive list of specific PDE-containing signalosomes, and include the specific PDE isoform and its signalling or interacting partners 
(both inferred and identified), the subcellular compartment or 'address' of the signalosome and the signalling pathway or cellular function regulated by the specific signalosome.

The integration of individual PDEs into specific signalosomes within different functional compartments has dramatically delineated the functional roles of individual PDEs and clearly linked the large number of PDE isoforms to the compartmentalized regulation of specific cyclic nucleotide signalling pathways and biological responses (TABLES 1,3). For example, PDE4B, PDE4D and PDE3A - as components of different, specifically localized, AKAP-based signalosomes in rodent cardiomyocytes - may regulate cAMP signalling within distinct cellular domains that regulate largely non-overlapping functions related to myocardial contractility (BOX 2; FIG. 3). From a teleological perspective, the large number of known PDE isoforms readily meets the demands of the compartmentalized regulation of individual cyclic nucleotide signalling pathways, with its inherent requirement to tether or target different PDEs to specific signalosomes at many different intracellular locations ${ }^{55-60}$. The incorporation of different types of PDEs into specific signalosomes (that is, PDEs from different PDE families and subfamilies or from different splice, transcriptional or translational variants, and so on), with their distinct intrinsic characteristics and regulatory properties, contributes to both the fine-tuning and specificity of compartmentalized cyclic nucleotide signalling ${ }^{1-3,13,14}$. In addition, different PDE isoforms can integrate multiple distinct cellular inputs and allow crosstalk between cyclic nucleotides and other signalling networks and systems ${ }^{13,14,58,59,61-64}$.

\section{Box 2}

\section{Signalosome coupling of CAMP-PKA signalling to myocardial contractility}

In the rodent heart, activation of $\beta$-adrenergic receptors increases myocardial contractility by coupling cAMP-protein kinase A (PKA) signalling to intracellular calcium cycling ${ }^{166}$. PKA-induced phosphorylation of L-type calcium channels in T-tubules and of ryanodine-sensitive calcium channels (also known as ryanodine receptor 2 (RYR2)) in the sarcoplasmic reticulum (SR) increase calcium influx and calcium-induced calcium release from the SR during systole, respectively. Phosphorylation of phospholamban (PLB) blocks its inhibitory interactions with sarcoplasmic/endoplasmic reticulum calcium ATPase 2 (SERCA2), the calcium-transporting ATPase of the SR, and results in increased calcium accumulation in the SR during diastole ${ }^{166}$ (FIG. 3). These actions increase the amplitude of myocardial calcium transients, resulting in enhanced inotropic and lusitropic responses.

As components of different A-kinase anchor protein (AKAP)-based signalosomes, phosphodiesterase 4B (PDE4B), PDE4D and PDE3A each regulate different phases of the calcium-mediated excitation-contraction coupling cycle ${ }^{166}$. AKAP15/AKAP18 is important in the targeting and tethering of PKA and PDE4B to L-type calcium channels; AKAP6 (also known as mAKAP) in the targeting and tethering of PDE4D to RYR2; and AKAP18 $\delta$ in the targeting and tethering of PDE3A to SERCA2-PLB regulatory complexes (known as signalosomes) ${ }^{167-169}$. In this manner, PDE4B regulates cAMPPKA-stimulated calcium influx, PDE4D regulates calcium-induced calcium release from 
the SR, and PDE3A regulates increased accumulation of calcium in the $\mathrm{SR}^{167-169}$. A PDE4D variant has also been reported to associate with SERCA2 in the rodent heart ${ }^{170}$.

Studies in $P d e 4 b$ - and $P d e 4 d$-knockout mice strongly suggest that compartmentalized PDE4B and PDE4D are crucial for maintaining the physiological equilibrium between PKA-induced channel phosphorylation and excitation-contraction coupling, as hyperphosphorylation of L-type calcium channels and RYR2 channel proteins in Pde $4 b$ and $P d e 4 d$-knockout mice (owing to increased cAMP-PKA signalling), respectively, leads to alterations in intracellular calcium cycling, ventricular arrhythmias and cardiac dysfunction ${ }^{167-169}$. In the rodent heart, a macromolecular complex containing the phosphoinositide 3-kinase $\gamma$-subunit (PI3K $\gamma$ ), PDE3A, PDE4A and PDE4B was recently proposed to have a protective role against ventricular arrhythmias by regulating the phosphorylation of L-type calcium channels and PLB ${ }^{171}$. Although PDE4 protects against cAMP-PKA-induced arrhythmias in isolated human atrial myocytes ${ }^{172}$, the role of PDE4 isoforms in human cardiac function is uncertain, as there are potential cardiovascular risks that might accompany the chronic usage of drugs such as roflumilast (approved for the treatment of chronic obstructive pulmonary disease), which inhibit all PDE4 isoforms. A recent report has identified a crucial role for PDE3, but not PDE4, in regulating $\beta_{1}$ - and $\beta_{2}$-adrenergic receptor-mediated effects on myocardial contractility in the hearts of patients with heart failure ${ }^{173}$.

Although this substantial expansion in knowledge has revealed many new therapeutic opportunities, it has also raised additional questions and challenges regarding the development of specific therapeutics and the design of novel targeting strategies. Advances in the identification of protein components of signalosomes, in the biochemical understanding of protein-protein interactions and in the structural insights provided by $\mathrm{X}$ ray crystallographic analyses of PDE catalytic cores and PDE-inhibitor co-crystal complexes, as well as more complex structures, are allowing optimization of the structurebased design of competitive inhibitors that are selective for particular PDE families and subfamilies (BOX 1; TABLE 2). These advances are also beginning to permit the targeting of intramolecular interactions between the regulatory and catalytic regions of PDE molecules ${ }^{18,35}$, as well as the targeting of intermolecular protein-protein interactions between PDEs and their regulatory partners ${ }^{13,14,19,58,59,61-65}$. There is hope and confidence that this emerging confluence between PDE biology and structure-based drug design, together with the development of more sophisticated strategies to target specific PDEs in complex with their signalosome partners, will hasten the development of third-generation allosteric modulators and signalosome disruptors targeting individual PDEs that could be used to treat a broad range of diseases.

\section{Biological and pathological roles of PDEs}

Family-selective PDE inhibitors have been valuable in delineating the specific signalling pathways and cellular functions that are regulated by specific PDEs in animals and isolated cells $^{1-3}$ (TABLE 2). However, the inability of most available agents to distinguish between the large numbers of family-specific isoforms expressed in most cells limits their value as probes to some extent. More compelling are studies of PDE-knockout mice, studies in which 
specific PDEs have been knocked down with small interfering RNA (siRNA) or studies highlighting the association of different PDE mutations with specific human diseases.

Indeed, data from these studies clearly demonstrate that the regulation of many cAMP- and cGMP-signalling pathways by specific PDEs is non-redundant, genetically determined and likely to be highly targetable (TABLES 1,2). For example, conclusive evidence that PDE3A is crucial for oocyte maturation was obtained when it was found that female Pde3aknockout mice are sterile, most probably because PDE3A in oocytes regulates a specific cAMP pool that controls the activation of maturation-promoting factor (which is formed from the gene products of cyclin-dependent kinase $1(C D K 1)$ and cyclin B1 $(C C N B 1))^{66,67}$. Thus, Pde3a-knockout mice provide proof of principle that oocyte PDE3A could be a valuable contraceptive target; this hypothesis is supported by the fact that PDE3-selective inhibitors prevent pregnancy in rodents and block the maturation of cultured oocytes in many species, including rodents and humans ${ }^{66,67}$. Results from similar experimental approaches have described numerous physiological and pathological roles of PDEs, as discussed below and in TABLES 1-3, and have thus encouraged the design and testing of new family-selective PDE inhibitors for use in numerous indications (TABLES 2,4).

Several human diseases are associated with mutations in genes encoding individual PDEs, or with mutations in genes encoding proteins that are involved in the expression or function of these PDEs (TABLE 1). For example, mutations in PDE6A and PDE6B are associated with autosomal recessive retinitis pigmentosa ${ }^{68,69}$, whereas mutations in AILPl (the gene encoding aryl hydrocarbon receptor-interacting protein-like 1), a chaperone of PDE6A, allow proteolytic destruction of PDE6A and are likely to cause Leber congenital amaurosis type 4 , a severe form of childhood blindness ${ }^{70}$. Partly because excess cGMP accumulation is associated with retinal degeneration in model systems ${ }^{71}$, the use of certain PDE5 inhibitors (for example, sildenafil and vardenafil) is contraindicated in patients with retinal degeneration ${ }^{72}$. Similarly, human PDE4D haplotypes and single-nucleotide polymorphisms (SNPs) have been correlated with ischaemic stroke ${ }^{73}$ and with responses to short-acting bronchodilators in paediatric asthma ${ }^{74}$, whereas PDE4B SNPs correlate with schizophrenia $^{75}$. PDE8B expression regulates cAMP-mediated steroidogenesis ${ }^{76,77}$, and $P D E 8 B$ mutations are associated with isolated adrenal micronodular hyperplasia and other human adrenal adenomas ${ }^{78,79}$. Inactivating PDE11A mutations were described in a subgroup of patients with Cushing syndrome and bilateral micronodular adrenal hyperplasia ${ }^{80}$. Also, certain PDE11 mutations may increase susceptibility to prostate cancer ${ }^{81}$ or to adrenal and testicular tumours in patients with Carney complex ${ }^{82}$, a disease that may be associated with inactivating mutations in the cAMP-dependent protein kinase type 1 alpha regulatory subunit (PRKARIA) gene.

Alterations in cyclic nucleotide signalling pathways also affect neoplastic cellular transformation, tumour cell growth, progression and metastasis, as well as tumour cell function ${ }^{83,84}$. Numerous PDE1- to PDE5-selective inhibitors, as well as PDE7-selective inhibitors, have been reported to inhibit growth and induce apoptosis in many different human cancer cell lines, which suggests a potential role for these drugs as antineoplastic agents (TABLES 1,2). For example, elevated $P D E 7 B$ expression is associated with poor prognosis in chronic lymphocytic leukaemia (CLL), and selective PDE7 inhibitors 
(BRL-50481 and IR-202) increase cAMP-PKA signalling and apoptosis in CLL cells ${ }^{85}$. These data identify PDE7B as both a biomarker and a target for treating CLL. Similarly, inhibition of PDE4 activity or knockdown of PDE4D expression in malignant cells with elevated PDE4 activities caused growth inhibition and apoptotic cell death in the malignant cells, but not in the non-malignant cells ${ }^{86,87}$. Re-expression of PDE4D inhibited cell death, which suggests that PDE4D might be both a tumour promoter and a therapeutic target in certain cancers. These beneficial effects of reducing PDE-mediated cAMP hydrolysis should, however, be tempered, given that cAMP can promote the growth of certain carcinomas and that apparently inactivating mutations in some PDEs (for example, PDE8 and $P D E 11$ ) can predispose to endocrine tumours ${ }^{88,89}$. The effects of PDE inhibitors on the permeability of the blood-brain barrier may also alter the effects of other therapeutic agents 90 .

cAMP and cGMP signalling pathways are important in cognition as well as in behavioural function and dysfunction (TABLES 1,2). Results of recent studies confirm that certain PDEs may be targets for ameliorating cognitive or behavioural deficits. Indeed, the PDE4 inhibitor rolipram, which was initially developed as an antidepressant ${ }^{91}$, improves cognition and long-term memory in rodents $35,92,93$. At a molecular level, the observation that Pde $4 d$ knockout mice exhibit antidepressive behaviour and show reduced antidepressant responses to rolipram but not to other antidepressant drugs supports a role for PDE4D in cognition, memory and antidepressive behaviour, whereas $P d e 4 b$-null preclinical models implicate this enzyme in anxiety-related behaviour ${ }^{35,92,93}$. Mutations in DISC1 (disrupted in schizophrenia homolog 1) and polymorphisms in $P D E 4 B$ are both associated with schizophrenia ${ }^{75}$, and DISC1 and PDE4B interact physically in cells to influence the catalytic activity of PDE4B 94,95 ; together, these observations support the notion that PDE4B is involved in schizophrenia. In preclinical rodent models, highly selective PDE10A inhibitors elicited anti-psychotic and pro-cognitive responses, and also increased sociality ${ }^{41,42,93}$ (TABLE 2). Also, inhibition of PDE4 or PDE10A alleviated motor and behavioural deficits in a transgenic R6/2 mouse model of Huntington's disease, in which alterations in striatal PDE10A preceded the motor symptoms of the disease ${ }^{96,97}$. These studies have increased interest in developing PDE inhibitors as therapeutics for basal ganglia disorders.

\section{PDE inhibitors in the clinic}

Although many high-affinity, PDE-family-selective, competitive inhibitors have been generated, only a limited number of second-generation agents have received regulatory approval for widespread clinical use. Below, we describe some of the agents that are in widespread use and those that may soon gain regulatory approval. A more comprehensive list of the agents that are currently under development and in clinical trials is provided in TABLE 2 and TABLE 4.

\section{PDE3 inhibitors}

Although PDE3 inhibitors produce acute inotropic, lusitropic and vasodilatory haemodynamic responses in patients with heart failure $25,28,98$, chronic administration of the PDE3 inhibitor milrinone (Primacor; Astellas Pharma/Sanofi) in such patients increased annual mortality, most probably owing to arrhythmias and cardiac arrest ${ }^{98,99}$. Milrinone is 
approved, however, for the acute treatment of adults with decompensated and refractory heart failure, and those awaiting heart transplants ${ }^{98}$. Another PDE3 inhibitor, cilostazol (Pletal; Otsuka Pharmaceutical), is approved and widely used to treat intermittent claudication, a relatively common lower-extremity peripheral arterial disease that is characterized by ischaemia-induced leg pain or cramping ${ }^{100,101}$. Cilostazol increases walking distance and reduces the clinical symptoms of intermittent claudication by cAMPmediated vasodilation and the inhibition of platelet activation and vascular wall inflammation 100,101 .

\section{PDE4 inhibitors}

PDE4 isoforms have a relatively high level of expression in cells that regulate immunoinflammatory responses and tissue remodelling ${ }^{29}$. Because early PDE4-selective inhibitors - especially rolipram — exhibited potent cAMP-mediated anti-inflammatory responses in various cellular and animal models, pharmaceutical companies invested heavily in developing PDE4 inhibitors for clinically important, inflammation-related pulmonary diseases, including COPD, asthma, allergic rhinitis and idiopathic pulmonary fibrosis ${ }^{29-31}$. COPD is a major public health concern and a leading cause of death in societies where smoking is prevalent. Clinically, COPD is characterized by progressive airway inflammation and obstruction, as well as a decline in lung function, with acute recurrences and exacerbations that lead to a markedly reduced quality of life and eventual death. Although the development of rolipram and other PDE4 inhibitors was hampered owing to their gastrointestinal side effects, especially nausea, emesis and diarrhoea, the potential of the target encouraged further industry investment and led to the development of more advanced PDE4 inhibitors. Two inhibitors, cilomilast and roflumilast, reached Phase III trials ${ }^{29-31}$; roflumilast (Daliresp/Daxas; Takeda/Nycomed) is now approved as an oral treatment for reducing the risk of exacerbations in patients with COPD who also have chronic bronchitis $^{29-32}$ (TABLES 2,4).

\section{PDE5 inhibitors}

Male erectile dysfunction is a widespread and distressing condition and is often associated with significant co-morbidities, including hypertension, hyperlipidaemia, atherosclerosis and diabetes $^{33}$. As cGMP is a crucial physiological regulator of the nitric oxide-induced vasodilation (which leads to penile erection) that occurs upon sexual stimulation, and given that PDE5 has a relatively high expression in the corpus cavernosum, PDE5 inhibitors can be used to prevent the destruction of cGMP and thereby enhance erectile function in unaffected men or in patients with erectile dysfunction (secondary to deficiencies in nitric oxide-cGMP signalling) ${ }^{33}$. Orally administered PDE5 inhibitors, the first being sildenafil, followed by vardenafil and tadalafil (Cialis; Eli Lilly), have been highly successful in treating erectile dysfunction. Avanafil (Stendra; Vivus), a rapidly acting PDE5-selective inhibitor, has also been approved for the treatment of erectile dysfunction (TABLES 2,4).

Pulmonary arterial hypertension is characterized by increased mean pulmonary artery pressure and increased pulmonary vascular resistance resulting from vasoconstriction and hypertrophic structural remodelling of the small pulmonary arteries, which leads to decreased oxygenation of blood, dyspnoea, decreased exercise capacity, reduced quality of 
life, heart failure and, eventually, death ${ }^{34,102,103}$. PDE5, which has a relatively high expression in the airway and vascular smooth muscle, is thought to be a key regulator of pulmonary vascular dilation and remodelling via its modulation of cGMP-PKG signalling. PDE5 inhibitors such as sildenafil (marketed as Revatio by Pfizer), tadalafil (marketed as Adcirca by Eli Lilly) and vardenafil are currently approved for the treatment of pulmonary arterial hypertension ${ }^{34,102,103}$.

Today, xanthine derivatives (for example, theophylline and caffeine), which inhibit almost all PDE families (except for PDE8 and PDE9), are clinically used primarily as bronchodilators in the treatment of pulmonary diseases such as asthma, chronic bronchitis, emphysema and $\mathrm{COPD}^{20,21}$. Another xanthine derivative, pentoxifylline (Trental; Sanofi) is used to treat intermittent claudication secondary to chronic occlusive arterial disease. These drugs, however, exhibit a narrow therapeutic window, and toxicity (nausea, emesis and arrhythmias) is a major concern ${ }^{20}$. Theophylline is also currently being considered as an important add-on therapy in cortico-steroid-resistant asthma and COPD ${ }^{21}$ (ClinicalTrials.gov identifier: NTC00241631). Dipyridamole, another non-selective PDE inhibitor, inhibits platelet aggregation and is used to prevent post-surgical thromboembolic events and stroke ${ }^{104}$.

\section{Limitations of existing agents}

Despite the therapeutic success of several PDE3, PDE4 and PDE5 inhibitors, off-target effects limit their use. Although these inhibitors predominantly inhibit specific PDE families and not virtually all PDEs, as is the case with methylxanthines, they unfortunately inhibit all family members, even those in off-target locations, which produces undesirable effects. The importance of understanding these off-target effects is increasingly being realized, as they can both positively and negatively influence the risk-benefit profile of PDE inhibitors. For example, in the case of the PDE3 inhibitor milrinone, it is not known whether its cardiotoxicity is related to its inhibition of both PDE3A and PDE3B, its inhibition of different pools of cardiac PDE3A that differentially regulate contractility and apoptosis, its inhibition of other PDE families or to its interactions with non-PDE proteins ${ }^{98}$. Similarly, the PDE4 inhibitors rolipram and cilomilast failed in clinical trials because of the doselimiting nausea- and emesis-associated off-target effects caused by the inhibition of PDE4 isoforms, possibly PDE4D, in the emetic centre in the brain ${ }^{20,31}$.

Conversely, some off-target effects of family-selective PDE inhibitors can positively affect their efficacy and/or their safety profile. For example, it has been suggested that sildenafilinduced inhibition of PDE1 may be responsible for some of the beneficial effects of this PDE5 inhibitor in treating heart failure ${ }^{98,102}$. Indeed, PDE1 is more highly expressed than PDE5 in the human myocardium, and inhibition of PDE1 in preclinical models of heart failure blocks pathological vascular remodelling and cardiac hypertrophy ${ }^{105,106}$. Should the unexpected protective effects of sildenafil in the heart be related to PDE1 inhibition, these data would support the notion that dual PDE1 and PDE5 inhibition might be beneficial in treating human cardiovascular diseases. Similarly, the ability of cilostazol to block adenosine uptake into the myocardium (via mechanisms other than the inhibition of PDE3) may be related to the reduced cardiotoxicity observed during chronic administration of 
cilostazol as compared to that observed following the chronic administration of milrinone ${ }^{99-101,107}$.

The use of PDE family-selective inhibitors can also be limited by their direct or indirect inhibition of other PDE family enzymes and/or their interaction with non-PDE proteins to cause unacceptable toxicity, as well as by the roles of multiple PDE families in regulating signalling pathways. As for interacting with non-PDE proteins, the PDE5 inhibitor vardenafil has been reported to block calcium channels in rabbit pulmonary arteries and human platelets ${ }^{108}$, and sildenafil has been reported to interact with multidrug resistance protein 1 (MDR1; also known as ABCB1) and antigen peptide transporter 1 (APT1; also known as $\mathrm{ABCB} 2$ ) to block drug extrusion from cells ${ }^{109}$. This latter off-target effect could be potentially quite important in serving to reduce ABCB1- and ABCB2-mediated drug resistance and thus improve the efficacy of some chemotherapeutic agents, perhaps independently of PDE5 inhibition ${ }^{109,110}$.

Nonspecific PDE inhibitors may inhibit multiple PDEs and interact with many proteins, which may alter the efficacy of these compounds. For example, because the methylxanthine theophylline is a purine derivative, it inhibits almost all PDEs and also interacts with many other proteins, producing both beneficial and toxic effects ${ }^{31,111}$. Although the bronchodilatory effects of theophylline are most probably related to PDE inhibition in the airway smooth muscle, its anti-inflammatory actions - which are mediated in part via inhibition of the nuclear translocation of nuclear factor $-\kappa \mathrm{B}(\mathrm{NF}-\kappa \mathrm{B})-$ may be attributed to both PDE inhibition (similar to the effects of the PDE4 inhibitor NCS 613) ${ }^{112}$ and to increased cAMP signalling ${ }^{113,114}$, as well as to effects that are independent of this activity ${ }^{111,115}$. Indeed, theophylline directly activates phosphoinositide 3-kinase $\delta$-subunit $(\mathrm{PI} 3 \mathrm{~K} \delta$ ), which, in turn, activates histone deacetylases (HDACs) and thus augments the antiinflammatory effects of glucocorticoids ${ }^{111,115}$. Theophylline also binds to adenosine receptors, and although blocking adenosine $\mathrm{A}_{2 \mathrm{~B}}$ receptors may be beneficial in preventing adenosine-induced mediator release from mast cells, blocking adenosine $\mathrm{A}_{1}$ receptors could account for serious untoward effects, including cardiac arrhythmias and seizures ${ }^{31,111}$. Last, inhibition of PDE4 could account, in part, for theophylline-induced nausea and diarrhoea $^{31,111 .}$.

\section{New uses, drugs and development approaches}

The enormous clinical success of PDE5 inhibitors has spurred continued interest in PDE inhibitors as potential therapeutics as well as in approaches to overcome the limitations of current PDE inhibitors. In addition, the emerging concept that many individual PDEs or subsets of PDEs are selectively localized or recruited to specific cellular compartments where they are integrated into specific signalosomes provides insight into their specific functional roles in health and disease, as well as their potential as novel therapeutic targets.

The level of interest in PDE inhibitors can be readily appreciated from the large number of clinical trials registered on the ClinicalTrials.gov website; some of these trials are listed, along with their indications and associated NCT designations, in TABLE 4. Many of these trials are in Phase IV, involve US Food and Drug Administration (FDA)-approved PDE3, 
PDE4 and PDE5 inhibitors, and are designed to provide additional information about the efficacy of these inhibitors in subpopulations of currently targeted patients or in novel clinical applications (TABLES 2,4). In addition, a substantial number of trials (TABLE 4) are investigating novel PDE inhibitors in the treatment of diseases for which PDE inhibitors are already approved — that is, COPD, pulmonary hypertension and erectile dysfunction or for additional diseases. Trials investigating the use of PDE1 inhibitors for the treatment of vascular remodelling or schizophrenia, PDE7 inhibitors for the treatment of inflammation or leukaemia, and PDE10A inhibitors for the treatment of neuropsychological disorders are all in progress. Because of the complexity of many diseases, such as COPD, asthma and type 2 diabetes, there is also increasing interest in utilizing multiple PDE inhibitors or developing inhibitors that target several particular PDEs to provide more effective therapies with more favourable risk-benefit profiles.

\section{Novel applications of PDE inhibitors}

\section{PDE3 inhibitors}

A substantial number of trials are testing currently approved PDE inhibitors in other conditions (TABLE 4). For example, clinical studies have suggested that the PDE3 inhibitor cilostazol, perhaps owing to its anti-inflammatory effects as well as its ability to inhibit platelet aggregation and vascular smooth muscle proliferation ${ }^{100}$, may attenuate postangioplasty restenosis (the 'cilostazol for restenosis' (CREST) trial) ${ }^{116-118}$ or reduce the progression of atherosclerosis in diabetes (the randomized 'diabetic atherosclerosis prevention by cilostazol' (DAPC) trial) ${ }^{119,120}$. The vascular smooth muscle cell (VSMC)proliferation-stimulating component of this potential activity is underpinned by data obtained using VSMCs derived from Pde3a-null mice ${ }^{121}$. Aortic VSMCs of Pde $3 a$-deficient mice, but not those from $P d e 3 b$-null mice, exhibited dysregulated cAMP-PKA signalling and mitogen-activated protein kinase (MAPK) signalling as well as reduced mitogeninduced VMSC proliferation ${ }^{121}$.

PDE1 may also be a crucial regulator of pathological vascular and airway smooth muscle remodelling ${ }^{105}$. In normal vessels, VSMCs exhibit a quiescent or contractile phenotype, which is geared to maintain vascular tone. In response to injury and/or endothelial dysfunction, VSMCs shift to a synthetic or proliferative phenotype in which the induction of PDE1C removes the inhibitory effects of cAMP on growth. siRNA-induced knockdown of PDE1A or pharmacological inhibition of PDE1A with IC83640 (a PDE1-selective inhibitor) blocked cell cycle progression in proliferating VSMCs ${ }^{105}$. Similarly, PDE1C knockdown in VSMCs derived from pulmonary hypertensive arteries increased cAMP and inhibited proliferation $^{105}$. Thus, targeting PDE1C $\mathrm{C}^{105}$ and/or PDE3A $\mathrm{A}^{121}$ in vessels might, via increased cAMP signalling, block the growth of VSMCs and reduce the vascular remodelling that occurs in pulmonary hypertension, atherosclerosis, post-stenting restenosis and after angioplasty, as well as certain cardiomyopathies.

\section{PDE4 inhibitors in inflammatory disorders}

Given their potent anti-inflammatory effects, PDE4 inhibitors might be useful for treating diseases involving aberrant immune responses, such as atopic dermatitis, rheumatoid 
arthritis, systemic lupus erythematosus, psoriasis, inflammatory bowel disease and type 1 diabetes $^{29-31,35,122,123}$. As shown in TABLE 4, apremilast - a second-generation PDE4 inhibitor - is in Phase II and Phase III trials for use in psoriasis and psoriatic arthritis ${ }^{31,123}$. Studies with $P d e 4 a-, P d e 4 b$ - and $P d e 4 d$-null mice ${ }^{124-126}$ demonstrated that only the $P d e 4 b$ null mice failed to develop airway inflammation (that is, $\mathrm{T}$ helper $2\left(\mathrm{~T}_{\mathrm{H}} 2\right)$ cytokine production and eosinophil infiltration) or acute airway hyperactivity in response to antigeninduced challenge ${ }^{92}$. Other findings are consistent with the idea that inhibition of PDE4D in particular, rather than other PDE4 isoforms, is associated with the dose-limiting gastrointestinal side effects of PDE4 inhibitors, whereas PDE4B seems to have an important role in acute activation of the $\mathrm{T}$ cell receptor (TCR) ${ }^{124-127}$. Studies such as these have provided the rationale for the development of PDE4B-selective inhibitors as potential therapeutics for allergic inflammation and asthma ${ }^{92}$, and the development of PDE4Dselective allosteric modulators (as discussed below) to reduce inflammation and improve $\operatorname{cognition}^{35}$.

Recent studies exploring the biology of the nonspecific PDE inhibitor resveratrol ${ }^{128,129}$ may have important implications for future clinical applications of PDE4 inhibitors. In animal models, resveratrol — a polyphenol found in red wine — protects against diet-induced obesity, type 2 diabetes and some of the cardiovascular complications associated with these disorders ${ }^{128}$. Indeed, recent findings have suggested that many of the pleiotropic beneficial effects of resveratrol may be mediated via its nonspecific inhibition of PDEs, especially PDE4, as the metabolic benefits of resveratrol in mice ${ }^{129}$ were mimicked by the inhibition of PDE4 with rolipram. Indeed, when compared to littermates that were fed a high-fat diet, $P d e 4 b$-knockout mice gained less weight and had less obesity-induced inflammation ${ }^{130}$. Perhaps more importantly, significant weight loss was reported in participants receiving roflumilast in clinical trials ${ }^{30}$. Roflumilast has also recently been reported to reduce levels of glycated haemoglobin and blood glucose in patients with newly diagnosed type 2 diabetes ${ }^{131}$. Thus, PDE inhibitors, especially PDE4 inhibitors, may be useful for treating certain metabolic diseases, including obesity, type 2 diabetes and metabolic syndrome ${ }^{132}$. Given the current understanding of the crucial role of inflammation in these diseases ${ }^{133}$, the anti-inflammatory actions of PDE4 inhibitors may provide considerable therapeutic benefit.

\section{PDE5 inhibitors}

Clinical trials (TABLE 4) are in progress investigating PDE5 inhibitors in heart failure as well as in Duchene and Becker muscular dystrophy (the 'Revatio for Heart Disease in Duchenne and Becker Muscular Dystrophy' REVERSE-DBMD trial). Indeed, there is considerable excitement regarding the potential use of PDE5 inhibitors as therapeutics for cardiovascular diseases ${ }^{102}$, including hypertension, ischaemic cardiomyopathy, cardiac failure, stroke, peripheral myopathy and cardiac dysfunction in Duchenne muscular dystrophy, as well as insulin resistance, type 2 diabetes and metabolic

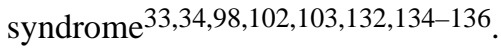

In rodent heart models of ischaemia-reperfusion injury, sildenafil has a cardioprotective effect and limits infarct size, perhaps by increasing cGMP-PKG signalling, which results in the opening of mitochondrial ATP-sensitive potassium channels, thus limiting the 
accumulation of calcium in mitochondria and preventing cell death ${ }^{102}$. In the rodent heart, sildenafil blocked the development of cardiac hypertrophy induced by trans-aortic constriction or by the $\beta$-adrenergic receptor agonist isoprenaline. Remarkably, in the $m d x$ mouse model of Duchenne muscular dystrophy, sildenafil prevented or reversed the cardiac dysfunction and cardiomyopathy characteristically observed in these mice. Similar to their effects on pulmonary circulation, PDE5 inhibitors may improve cerebral circulation and oxygenation and thus protect the brain against stroke ${ }^{102}$.

\section{PDE10 inhibitors and other PDE inhibitors in nervous system disorders}

PDE10 inhibitors are being considered as cognition enhancers and as therapeutics for cognitive dysfunction, based on preclinical studies that have demonstrated the beneficial effects of these agents on learning and memory as well as on cognitive and behavioural defects in complex neuropsychological disorders such as schizophrenia. As of 2012, for example, 25 PDE4 inhibitors and 10 PDE10A inhibitors had been granted patents that claimed a positive effect on learning and memory ${ }^{137}$. Another report ${ }^{138}$ indicated that more than 20 companies had published patent applications targeting PDE10A for central nervous system (CNS) research purposes, especially schizophrenia ${ }^{41,42,93}$. PDE10A inhibitors, which have been shown to have antipsychotic effects in rodent models ${ }^{41,42,138}$ and to exhibit antipsychotic and pro-cognitive effects as well as enhance social behaviour in mice ${ }^{139}$, are in clinical trials for the treatment of schizophrenia (TABLE 4). A PDE1 inhibitor, ITI-214, is in trials for the treatment of cognitive deficits associated with schizophrenia and other neuropsychiatric disorders ${ }^{140}$. Other companies are also developing PDE inhibitors to target these diseases (TABLE 4). There is also interest in utilizing inhibitors of PDE10A and PDE4 in Huntington's disease ${ }^{93,141}$ (TABLE 4).

\section{Combinatorial PDE inhibition}

Although individual PDEs regulate selective cAMP signalling pathways, the dysregulation of multiple signalling pathways contributes to the pathogenesis and clinical presentations of complex diseases such as COPD and diabetes ${ }^{142,143}$. It is therefore likely that several PDEs may need to be targeted for effective treatment. Targeting multiple PDEs (with multiple drugs or with individual drugs that have mixed selectivities) in several target cells could theoretically produce additive or synergistic effects and lead to more effective therapies, so that drugs could perhaps be administered at lower doses and induce fewer side effects (TABLES 2,4). Novel second-generation, non-selective PDE inhibitors (analogous to theophylline and resveratrol) might also provide simultaneous inhibition of multiple PDEs and the activation of several signalling pathways, thereby producing additive or synergistic beneficial effects in these and other complex diseases.

A major impetus to consider dual PDE inhibitor therapy relates to the desire to take full advantage of the powerful anti-inflammatory effects of PDE4 inhibitors, such as roflumilast, as the narrow window between their anti-inflammatory effects and their side effects (which include nausea and emesis) may limit their application in many inflammatory diseases. The anti-inflammatory effects of PDE4 inhibitors are not identical in all immunoinflammatory cells, and inhibitors of PDE7 and PDE3 can enhance the effects of PDE4 inhibitors in T cells and macrophages, respectively $31,143,144$. With respect to diseases such as asthma, 
PDE4 inhibitors are not broncho- or vasodilators. Thus, although new PDE4 inhibitors with reduced emetic effects are in development (for example, the PDE4D allosteric modulator D159687) $)^{31,35}$, a combinatorial approach could maximize the efficacy of PDE4 inhibitors without adversely affecting their risk-benefit ratios ${ }^{143,145}$.

\section{Dual PDE8-PDE4 inhibitors}

Studies utilizing family-selective PDE8 inhibitors, as well as studies using Pde8a-knockout mice, $P d e 8 b$-knockout mice and $P d e 8 a^{-1-} P d e 8 b^{-1-}$ double-knockout mice, demonstrated that PDE8A and PDE8B have both specific and overlapping roles in regulating the basal rates of steroid production in rodent Leydig and adrenal cells ${ }^{76,77}$. PDE8 inhibitors, however, clearly synergized with PDE4 inhibitors in regulating the maximal rates of cAMPstimulated steroidogenesis ${ }^{77}$. These studies clearly demonstrated that functionally interacting cAMP pools or compartments can be regulated by multiple PDEs.

\section{Dual PDE1-PDE4 inhibitors}

There is evidence indicating that combined PDE1 and PDE4 inhibitors could have utility in pathological airway remodelling (mediated by PDE1) and pulmonary inflammation ${ }^{105,143}$. Airway remodelling (thickening of the wall owing to hyperplasia or hypertrophy) and increased airway hyperreactivity are characteristic of the pro-inflammatory phenotypes of asthma and COPD. PDE1 inhibitors block smooth muscle mitogenesis and could complement the anti-inflammatory effects of PDE4 inhibitors ${ }^{105,143}$. KF19514, which inhibits both PDE1 and PDE4, was reported to reduce airway remodelling and inflammation in a murine model of asthma ${ }^{143,145}$.

\section{Dual PDE4-PDE7 inhibitors}

PDE7A is widely expressed in immunoinflammatory cells, especially $\mathrm{T}$ lymphocytes, but its functional role is not certain, and selective PDE7 inhibitors do not markedly alter normal T cell function ${ }^{143,144}$. However, the co-expression of PDE4 and PDE7 in most immunoinflammatory cells and the synergistic effects of PDE7- and PDE4-selective drugs in the suppression of inflammation in cell-based studies have fuelled speculation that dual inhibition of PDE7 and PDE4 could be an effective strategy to treat asthma, COPD and other diseases characterized by a pro-inflammatory phenotype ${ }^{143,146}$.

\section{Dual PDE3-PDE4 inhibitors}

As PDE3 inhibitors ${ }^{147}$ are bronchodilators and, similar to PDE7 inhibitors, they increase the effects of PDE4 inhibitors in immunoinflammatory cells (especially macrophages) ${ }^{143,148}$, several pharmaceutical companies have developed inhibitors with dual selectivity for PDE3 and PDE4 as potential therapeutics for asthma and COPD ${ }^{145,148,149}$ (TABLES 2,4). So far, no lead scaffolds generated through structure-based design have been reported. Some attempts have generated hybrid compounds with distinct PDE3 and PDE4 pharmacophores separated by a linker ${ }^{149}$. Two early dual PDE3-PDE4 inhibitors (zardaverine and benafentrine) had modest and short-lived bronchodilatory effects in humans ${ }^{150}$. Another PDE3-PDE4 inhibitor, RPL554 (a pyrimido-isoquinolinone derivative with $\mathrm{IC}_{50}$ values of 
$107 \mathrm{nM}$ and $1.2 \mu \mathrm{M}$ for PDE3 and PDE4, respectively), is in trials for COPD, allergic rhinitis and asthma ${ }^{151}$.

Alternative approaches for targeting PDE4 in pulmonary disease include the development of inhaled PDE4 inhibitors or inhaled antisense oligonucleotides targeting specific PDE4 isoforms, as well as combinations of PDE4 inhibitors and inhaled corticosteroids or $\beta$ adrenergic receptor agonists. For example, the inhaled PDE4 inhibitor GSK256066 significantly reduced early and late responses to inhaled allergen in a small trial studying 24 patients with asthma ${ }^{152}$. In COPD, roflumilast can be used alone or together with standard bronchodilator treatments, such as salmeterol (a long-acting $\beta_{2}$-adrenergic receptor agonist (LABA)) or tiotroprium (a short-acting anticholinergic drug) ${ }^{30,145}$.

\section{Novel signalosome disruptors}

As discussed above, individual PDEs are recruited in an isoform-specific manner into specialized signalosomes within discrete functional compartments, where they can tightly regulate local cyclic nucleotide concentrations and gradients ${ }^{13,153}$ (TABLE 3). As a corollary to the signalosome hypothesis, there are data supporting the therapeutically relevant proposition that the disruption of cyclic nucleotide-mediated events within specific individual signalosome-based compartments will have more specific effects than agents that do not discriminate between these compartments and instead inhibit other members of the same PDE family $9,61-65$.

It should be possible to target events that are coordinated by individual signalosomes. This could be achieved by disrupting the integration of individual proteins into these signalosomes during their formation or, more conceivably, by displacing individual proteins from pre-formed or dynamically forming signalosomes in cells using small-molecule antagonists ${ }^{154,155}$ or 'disruptor peptides' 156 to antagonize protein-protein interactions. Examples of small molecules or peptides include those designed to displace PKA regulatory subunits from AKAPs ${ }^{154,155}$ or other scaffolding proteins ${ }^{156-159}$, peptides designed to antagonize the interaction of PDEs with cyclic nucleotide effectors ${ }^{19,57}$, and peptides designed to disrupt PDE-EPAC interactions ${ }^{57,62,63}$ (FIG. 4).

Peptide-based therapeutic agents have some advantages over traditional small-molecule drugs, such as their high potency and selectivity, their low toxicity and biological accumulation in tissues as well as their high diversity. Conversely, their physicochemical properties make them unsuitable for simple oral delivery, and without modification they have relatively poor bioavailability and low metabolic stability. Indeed, small unconjugated linear peptides composed exclusively of natural amino acids are easily degraded by numerous peptidases and are efficiently removed from the circulation by the kidney. However, although these disadvantages have limited the use of peptide-based therapeutics, recent advances with the potential to dramatically enhance the membrane permeability and metabolic stability of these agents are increasingly enabling their clinical use ${ }^{160}$. 


\section{Disruptors of targeted PDEs \\ PDE4}

In human arterial endothelial cells (HAECs), the inhibitory effects of cAMP on cell permeability, mediated via the activation of EPAC1-RAP1 (small GTPase RAS-related protein 1) signalling, are regulated through a PDE4D-containing, EPAC1-based, cAMP signalo-some ${ }^{57,62,63}$ (FIG. 4). The use of traditional PDE4 inhibitors (such as rolipram and Ro20-1724) or an EPAC1-based PDE4D-disrupting peptide led to the activation of RAP1 by EPAC1 within this complex and promoted HAEC barrier integrity (FIG. 4). Further studies are needed to assess the impact of disrupting PDE4D- or EPAC1-mediated endothelial barriers in vivo under conditions of vascular inflammation. Similarly, in isolated cardiomyocytes, a peptide that selectively disrupted the association of PDE4D5 with heat shock protein 20 (HSP20) increased local cAMP-PKA-induced phosphorylation of HSP20 and reduced the catecholamine-induced hypertrophic response in this model system ${ }^{19,161}$. Such an approach could have utility in limiting cardiac hypertrophy, and studies to test this hypothesis are underway.

Although these studies highlight the functional consequences of disrupting these complexes in cells, further studies will be required to assess their functional selectivity in more physiological settings. Indeed, in the context of displacing PDE4D5 in cardiomyocytes, this approach might be limited by potentially arrhythmogenic effects resulting from cAMPPKA-induced hyperphosphorylation of the L-type calcium channel (BOX 2). In this context, studies with Pde4b-knockout mice highlight the potential benefits of targeting PDE4Bcontaining signalosomes in immunoinflammatory cells in conditions including COPD and asthma ${ }^{92,162}$, as opposed to the potentially arrhythmogenic effects of targeting PDE4Bcontaining signalosomes in cardiomyocytes (BOX 2). Finally, in a breast cancer cell model system, a peptide that selectively blocked the interaction between PDE4D5 and the scaffold protein RACK1 - in a complex composed of focal adhesion kinase (FAK), RACK1 and PDE4D5 - inhibited the invasion potential of the cultured cancer cells and might provide a novel avenue for limiting the invasion of certain cancer cells ${ }^{157}$.

\section{PDE3}

In the same HAEC cultures in which barrier function was shown to be locally regulated by a PDE4D- and EPAC1-based signalosome, a PDE3B-containing, EPAC1-based cAMP signalosome was also shown to selectively coordinate the effects of cAMP on HAEC adhesion, migration and tubule formation via the control of RAS-related protein (RRAS) and PI3K $\gamma$ signalling ${ }^{57}$ (FIG. 4). As with the PDE4D-EPAC1 complex that regulated HAEC permeability, the addition of either a PDE3 inhibitor (cilostamide) or of a PDE3B-based EPAC1-disruptor peptide promoted cAMP-mediated activation of RRAS and the RRASdependent activation of PI3K $\gamma^{62,63}$. Further studies will be required to determine how this avenue might be used to control angiogenesis in both wound healing and metastasis.

\section{PDE8A}

Recently, a crucial role was identified for the formation of a PDE8B-RAF1 complex in the control of PKA-dependent phosphorylation and inactivation of RAF1 in cells. Brown and 
co-workers ${ }^{65}$ reported that a PDE8A-based RAF1-disrupting peptide promoted PKAmediated phosphorylation of RAF1 in cells and thus provided mechanistic insights into the manner by which localized hydrolysis of cAMP has a crucial role in PKA-mediated phosphorylation and inhibition of RAF1. Given the importance of RAF1-mediated signalling in numerous systems, this mechanism may allow selective regulation of RAF1 activity in cells in which the actions of RAF1 are maladaptive, such as certain cancers.

Although we are only now beginning to identify where PDE-based signalosomes form and operate in cells, based on these examples it is likely that disrupting peptides, or small molecules with similar types of activities, will prove to be fruitful new therapeutic tools in the near future (TABLE 3).

\section{Allosteric modulators}

$\mathrm{N}$-terminal regulatory domains in certain PDEs contain structural determinants that are essential for PDE oligomerization, and although some of these have been suggested to regulate the catalytic activity of PDEs, these regions have not yet been targeted in the development of PDE activators or inhibitors. For instance, PDE2, PDE5 and PDE6 family enzymes contain homologous N-terminal GAF domains (FIGS 1,5a), which, upon cGMP binding, promote cyclic nucleotide hydrolysis via allosteric regulation of the distant Cterminal catalytic domain ${ }^{3,46}$. Similarly, two N-terminal domains, termed upstream conserved region 1 (UCR1) and UCR2 (FIGS 1,5b,c), form a functional module that regulates the catalytic activity of PDE4 as well as its oligomerization ${ }^{3,46,163}$. In this case, however, UCR-based regulation involves direct interactions between the UCR and the catalytic domain. A novel approach in the design of specific PDE inhibitors has focused on developing modulators that target and alter the interactions between $\mathrm{N}$-terminal regulatory domains and their downstream catalytic domains.

\section{GAF domain-based regulation}

Crystallographic data of homodimeric PDE2A (FIG. 5a) showed that unliganded PDE2A GAF domains (GAFA and GAFB) are arranged to form a parallel dimer that hinders the access of substrates to both catalytic domains of the dimeric PDE2A complex ${ }^{18,164}$. By contrast, the binding of cGMP to GAFB in PDE2A promoted the rotation of the monomeric catalytic domains, the removal of GAF-dependent steric hindrance and subsequent binding of the substrate ${ }^{18,164}$ (FIG. 5a). Using this information, a chimaera was constructed in which the GAF domains of PDE5A were fused to the cGMP- and GAF-regulated cyanobacterial adenylyl cyclase (CyaB1), and this chimaera was used in a high-throughput screen to identify compounds that inhibited GAF-mediated activation of CyaB1 by cGMP, but not cGMP-independent cyclase activity ${ }^{165}$. At least two specific GAF inhibitors, which blocked cGMP-induced activation of CyaB1, but not the intrinsic catalytic function of the cyclase, were discovered and are being characterized ${ }^{165}$.

\section{UCR-based regulation}

Although the cAMP binding pockets of PDE4 subfamilies (PDE4A, PDE4B, PDE4C and PDE4D) exhibit subtle conformational differences ${ }^{38}$, the variation within these active sites is 
small. As a result, PDE4 subfamily selectivity cannot be achieved just by targeting the active site. Analyses of crystal structures of PDE4B or PDE4D in complex with certain inhibitors, such as RS25344, have indicated that a UCR2 fragment interacts with the inhibitor at the active site, allowing for direct regulation of catalytic activity by the UCR2 domain $^{35,163}$. Crystallographic studies have identified three distinct homodimeric conformations of PDE4 subfamily enzymes. In the 'open' conformation, each active site has direct access to cAMP and functions independently ${ }^{38,163}$. As all PDE4 subfamily enzymes have a highly conserved active site, therapeutic agents that target this open conformer, including roflumilast, act as non-selective competitive inhibitors of all PDE4 enzymes (TABLE 2). In their 'closed' conformation, a C-terminal intramolecular helix in all PDE4 enzymes loops across the active site of each monomer to gate the access of cAMP to the catalytic site and to inhibit cAMP hydrolysis. In a third conformation, a UCR2-based helix from one monomer folds across and 'caps' the active site of the second monomer, and thus inhibits cAMP hydrolysis by the second monomer in 'trans' 15,163 (FIG. 5b,c). The equilibrium between the 'capped' and 'uncapped' states is influenced by extracellular signal-regulated kinase (ERK)-induced phosphorylation and specific inhibitors.

Structures of PDE4B or PDE4D3 in complex with certain inhibitors, including RS25344, have shown that RS25344 binds to the active site but also forms contacts with a helical fragment in the UCR2 domain. These interactions between UCR2 and RS25344 increased the affinity of the inhibitor for the PDE4D3 active site ${ }^{35,47,163}$ (FIG. 5b,c). UCR-mediated regulation of PDE4 activity is further regulated by the complex series of post-translational events and protein-protein interactions that PDEs are known to participate in ${ }^{13,92}$. It should be noted, however, that although interactions between UCR2 and certain PDE4 inhibitors at the active site induce conformational changes that result in an increased affinity of the inhibitor at the active site, UCR-mediated regulation involves physical 'capping' and interactions at the active site and thus does not induce classical allostery. Classical allostery involves conformational changes and the transduction of intra-molecular signals to the active site that arise through the interactions of ligands at regulatory sites that are distinct from the active site.

These multiple models have informed the development of PDE4D subtype-selective modulators that act as 'bidentate ligands' and bind simultaneously to both UCR2 and the active site to hold UCR2 in the closed position and partially inhibit PDE4 activity $35,47,163$. PDE4D subtype-selective inhibitors were designed by targeting a phenylalanine (in PDE4D) or tyrosine (in PDE4B) polymorphism in the UCR2 domain. One such PDE4D-selective allosteric regulator, D159687, was demonstrated to have potent anti-inflammatory effects in cell models and animal models, with minimal emesis, which suggests that it could have utility in inflammatory conditions such as COPD, asthma, psoriasis and arthritis ${ }^{35,163}$. In addition, studies in mice suggest that compounds like D159687 may have applications in improving cognitive function and memory, as well as in the treatment of depression. Based on this work, similar allosteric modulators acting at the UCR2 domain of PDE4B and the catalytic site of PDE4B might provide effective suppression of inflammation in asthma ${ }^{35,47,163}$. As sequences of the $\mathrm{N}$-terminal regulatory domains vary considerably across PDE families and subfamilies, it is anticipated that, given these early successes with 
allosteric modulators of PDE4, similar approaches aimed at antagonizing or promoting direct interactions between regulatory domains and catalytic sites in other PDEs will soon be underway.

\section{Concluding remarks}

Why are there so many PDEs? This question has been posed since the 1970s, well before the advent of molecular genetics. Based on the findings reviewed in this article, the signalosome concept has, in many respects, helped to provide the answer. Indeed, we suggest that the information reviewed herein is consistent with the notion that the tethering or targeting of individual PDEs to selected signalosomes at different subcellular locations allows individual PDEs to assume specific functional roles in the compartmentalized regulation of specific cyclic nucleotide signalling pathways, as well as physiological and pathophysiological responses. Moreover, as discussed above, we believe that by targeting individual signalosomes it will be possible to develop novel strategies to treat many diseases.

In addition, an increased understanding of the complexities of PDE biology, especially from the use of knockout and knockdown models of specific PDEs, has identified new targets for old and new drugs. These include PDE5 inhibitors for cardiovascular and metabolic diseases, PDE1C and PDE3A inhibitors for vascular remodelling, PDE1 and PDE10A inhibitors for schizophrenia, PDE7 inhibitors for inflammation, PDE4 inhibitors for diabetes, as well as PDE inhibitors in combination with other therapeutic modalities. This increased knowledge has also provided a conceptual framework for using multiple PDE inhibitors, inhibitors with mixed selectivities or non-selective inhibitors for complex diseases (TABLES 1,2,4).

As described above, the design of novel selective inhibitors is being increasingly driven by this improved understanding of the biology of PDEs and PDE inhibitors, as well as by structural insights from modern proteomics and X-ray crystallography of PDE catalytic cores and PDE-inhibitor co-crystal complexes, in addition to more complex structures. These studies have yielded information about the unique allosteric interactions between the regulatory and catalytic domains of PDEs, as well as between individual PDEs and their specific interacting partners (FIGS 4,5; TABLES 2-4). The design and delivery of novel selective agents, especially allosteric modulators (for example, PDE4D-selective inhibitors) and signalosome disruptors, will be challenging, but offers huge opportunities for the development of more specific and effective therapeutics.

\section{Supplementary Material}

Refer to Web version on PubMed Central for supplementary material.

\section{Acknowledgments}

V.M., J.C. and F.A. were supported by the National Heart, Lung and Blood Institute (NHLBI) Intramural research Program at the US National Institutes of Health (NIH) in Bethesda, Maryland, USA. Research funding for D.H.M. is from the Canadian Institutes of Health Research (CIHR). 


\section{Glossary}

\section{Cyclic nucleotide phosphodiesterase}

Signalosomes
(PDE). A large gene superfamily of isozymes that catalyse the hydrolysis of the important intracellular messengers cAMP and cGMP

Localized macromolecular complexes, formed via protein-protein interactions, that contain cyclic nucleotide effectors and regulate the subcellular compartmentalization of specific cyclic nucleotide signalling pathways. The incorporation of specific phosphodiesterases (PDEs) into signalosomes has established the crucial roles of individual PDEs in regulating specific cyclic nucleotide signalling pathways. This knowledge has spurred the development of more sophisticated strategies to target individual PDE variants and their interacting partners

\section{References}

1. Conti M, Beavo J. Biochemistry and physiology of cyclic nucleotide phosphodiesterases: essential components in cyclic nucleotide signaling. Annu Rev Biochem. 2007; 76:481-511. [PubMed: 17376027]

2. Francis S, Blount M, Corbin J. Mammalian cyclic nucleotide phosphodiesterases: molecular mechanisms and physiological functions. Physiol Rev. 2011; 91:651-690. This is an excellent, comprehensive and very timely review of PDEs. [PubMed: 21527734]

3. Keravis T, Lugnier C. Cyclic nucleotide phosphodiesterase (PDE) isozymes as targets of the intracellular signalling network: benefits of PDE inhibitors in various diseases and perspectives for future therapeutic developments. Br J Pharmacol. 2012; 165:1288-1305. This is an excellent and concise review of PDEs. [PubMed: 22014080]

4. Derbyshire E, Marletta M. Structure and regulation of soluble guanylate cyclase. Annu Rev Biochem. 2012; 81:533-559. [PubMed: 22404633]

5. Potter LR. Regulation and therapeutic targeting of peptide-activated receptor guanylyl cyclases. Pharmacol Ther. 2011; 130:71-82. [PubMed: 21185863]

6. Pierre S, Eschenhagen T, Geisslinger G, Scholich K. Capturing adenylyl cyclases as potential drug targets. Nature Rev Drug Disc. 2009; 8:321-335.

7. Tamm M, Richards DH, Beghé B, Fabbri L. Inhaled corticosteroid and long-acting $\beta_{2}$-agonist pharmacological profiles: effective asthma therapy in practice. Respir Med. 2012; 106:S9-S19. [PubMed: 23273165]

8. Parkes DG, Mace KF, Trautmann ME. Discovery and development of exenatide: the first antidiabetic agent to leverage the multiple benefits of the incretin hormone, GLP-1. Expert Opin Drug Discov. 2013; 8:219-244. [PubMed: 23231438]

9. Boden WE, et al. Nitrates as an integral part of optimal medical therapy and cardiac rehabilitation for stable angina: review of current concepts and therapeutics. Clin Cardiol. 2012; 35:263-271. [PubMed: 22528319]

10. Eindhoven JA, van den Bosch AE, Jansen PR, Boersma E, Roos-Hesselink JW. The usefulness of brain natriuretic peptide in complex congenital heart disease: a systematic review. J Am Coll Cardiol. 2012; 60:2140-2149. [PubMed: 23021324]

11. Rall T, Sutherland E. Formation of a cyclic adenine ribonucleotide by tissue particles. J Biol Chem. 1958; 232:1065-1076. [PubMed: 13549487]

12. Rall T, West $\mathrm{T}$. The potentiation of cardiac inotropic responses to norepinephrine by theophylline. J Pharmacol Exp Ther. 1963; 139:269-274. [PubMed: 13990605] 
13. Houslay MD, Baillie GS, Maurice DH. cAMP-Specific phosphodiesterase-4 enzymes in the cardiovascular system: a molecular toolbox for generating compartmentalized cAMP signaling. Circ Res. 2007; 100:950-966. [PubMed: 17431197]

14. Kritzer MD, Li J, Dodge-Kafka K, Kapiloff MS. AKAPs: the architectural underpinnings of local cAMP signaling. J Mol Cell Cardiol. 2012; 52:351-358. [PubMed: 21600214]

15. Ke H, Wang H. Crystal structures of phosphodiesterases and implications on substrate specificity and inhibitor selectivity. Curr Top Med Chem. 2007; 7:391-403. This report is an extensive summary of the three-dimensional structures of PDE families. [PubMed: 17305581]

16. Card GGL, et al. Structural basis for the activity of drugs that inhibit phosphodiesterases. Structure. 2004; 12:2233-2247. [PubMed: 15576036]

17. Manallack DT, Hughes RA, Thompson PE. The next generation of phosphodiesterase inhibitors: structural clues to ligand and substrate selectivity of phosphodiesterases. J Med Chem. 2005; 48:3449-3462. [PubMed: 15887951]

18. Pandit J, Forman MD, Fennell KF, Dillman KS, Menniti FS. Mechanism for the allosteric regulation of phosphodiesterase 2A deduced from the X-ray structure of a near full-length construct. Proc Natl Acad Sci USA. 2009; 106:18225-18230. This article reports the first structure, of near-full-length PDE2A, among the PDE families. [PubMed: 19828435]

19. Lee LCY, Maurice DH, Baillie GS. Targeting protein-protein interactions within the cyclic AMP signaling system as a therapeutic strategy for cardiovascular disease. Future Med Chem. 2013; 5:451-464. This report describes novel concepts and approaches regarding the use of signalosome disruptors to therapeutically target cardiovascular disease. [PubMed: 23495691]

20. Schudt C, Hatzelmann A, Beume R, Tenor H. Phosphodiesterase inhibitors: history of pharmacology. Handb Exp Pharmacol. 2011; 204:1-46. [PubMed: 21695634]

21. Barnes PJ. Corticosteroid resistance in patients with asthma and chronic obstructive pulmonary disease. J Allergy Clin Immunol. 2013; 131:636-645. [PubMed: 23360759]

22. Thompson W, Appleman M. Cyclic nucleotide phosphodiesterase \& cyclic AMP. Ann NY Acad Sci. 1971; 185:36-41. [PubMed: 4330503]

23. Thompson W, Terasaki W, Epstein P, Strada S. Assay of cyclic nucleotide phosphodiesterase and resolution of multiple molecular forms of the enzyme. Adv Cycl Nucleotide Res. 1979; 10:69-92.

24. Keravis T, Wells J, Hardman J. Cyclic nucleotide phosphodiesterase activities from pig coronary arteries. Lack of interconvertibility of major forms. Biochim Biophys Acta. 1980; 613:116-129. [PubMed: 6246952]

25. Weishaar R, Cain M, Bristol J. A new generation of phosphodiesterase inhibitors: multiple molecular forms of phosphodiesterase and the potential for drug selectivity. J Med Chem. 1985; 28:537-545. [PubMed: 2985781]

26. Lugnier C, Schoeffter P, Le Bec A, Strouthou E, Stoclet J. Selective inhibition of cyclic nucleotide phosphodiesterases of human, bovine and rat aorta. Biochem Pharmacol. 1986; 35:1743-1751. [PubMed: 2423089]

27. Yamamoto T, et al. Selective inhibition of two cAMP PDEs partially purified from calf liver. Biochem. 1983; 258:14173-14177.

28. Movsesian M, Wever-Pinzon O, Vandeput F. PDE3 inhibition in dilated cardiomyopathy. Curr Opin Pharmacol. 2011; 11:707-713. [PubMed: 21962613]

29. Torphy T. Phosphodiesterase isozymes: molecular targets for novel antiasthma agents. Am J Resp Crit Care Med. 1998; 157:351-370. [PubMed: 9476844]

30. Rabe KF. Update on roflumilast, a phosphodiesterase 4 inhibitor for the treatment of chronic obstructive pulmonary disease. Br J Pharmacol. 2011; 163:53-67. [PubMed: 21232047]

31. Tenor H, et al. Pharmacology, clinical efficacy, and tolerability of PDE4 inhibitors: impact of human pharmacokinetics. Handb Exp Pharmacol. 2011; 204:86-119.

32. Fabbri LM, et al. Roflumilast in moderate-to-severe chronic obstructive pulmonary disease treated with longacting bronchodilators: two randomised clinical trials. Lancet. 2009; 374:695-703. [PubMed: 19716961]

33. Francis SH, Corbin JD. PDE5 inhibitors: targeting erectile dysfunction in diabetics. Curr Opin Pharmacol. 2011; 11:683-688. [PubMed: 21924956] 
34. Ghofrani HA, Osterloh IH, Grimminger F. Sildenafil: from angina to erectile dysfunction to pulmonary hypertension and beyond. Nature Rev Drug Disc. 2006; 5:689-702.

35. Burgin AB, et al. Design of phosphodiesterase 4D (PDE4D) allosteric modulators for enhancing cognition with improved safety. Nature Biotech. 2010; 28:63-70. This paper provides evidence that novel allosteric PDE4 inhibitors - that is, inhibitors whose affinity for the active site is regulated by their interaction with a helical peptide from the UCR2 of PDE4 - may decrease the toxicity of PDE4 inhibition without affecting efficacy.

36. Ke H, Wang H, Ye M. Structural insight into the substrate specificity of phosphodiesterases. Handb Exp Pharmacol. 2011; 204:121-132. [PubMed: 21695637]

37. Huai Q, Colicelli J, Ke H. The crystal structure of AMP-bound PDE4 suggests a mechanism for phosphodiesterase hydrolysis. Biochem. 2003; 42:15559-15564.

38. Wang H, et al. Structures of the four subfamilies of phosphodiesterase-4 provide insight into the selectivity of their inhibitors. Biochem J. 2007; 408:193-201. This paper reveals conformational differences among four PDE4 subfamilies, and this information has been especially useful for the design of PDE4-subfamily-selective inhibitors. [PubMed: 17727341]

39. Zhang K, Card G, Suzuki Y, Artis D. A glutamine switch mechanism for nucleotide selectivity by phosphodiesterases. Mol Cell. 2004; 15:279-286. [PubMed: 15260978]

40. Card GL, et al. A family of phosphodiesterase inhibitors discovered by cocrystallography and scaffold-based drug design. Nature Biotech. 2010; 28:38-41.

41. Ho GD, et al. The SAR development of dihydroimidazoisoquinoline derivatives as phosphodiesterase 10A inhibitors for the treatment of schizophrenia. Bioorg Med Chem Lett. 2012; 22:2585-2589. This paper discusses the development of PDE4 inhibitors using cocrystallography and scaffold-based drug design through the synthesis and screening of a relatively small number of compounds. [PubMed: 22377514]

42. Malamas M, Ni Y, Erdei J. Highly potent, selective, and orally active phosphodiesterase 10A inhibitors. J Med Chem. 2011; 54:7621-7638. [PubMed: 21988093]

43. Meng F, et al. Structure-based discovery of highly selective phosphodiesterase-9A inhibitors and implications for inhibitor design. J Med Chem. 2012; 55:8549-8558. [PubMed: 22985069]

44. Claffey MM, et al. Application of structure-based drug design and parallel chemistry to identify selective, brain-penetrant, in vivo active PDE 9A inhibitors. J Med Chem. 2012; 55:9055-9068. [PubMed: 23025719]

45. Verhoest PR, et al. Discovery of a novel class of phosphodiesterase 10A inhibitors and identification of clinical candidate 2-[4-(1-methyl-4-pyridin-4-yl-1H-pyr azol-3-yl)phenoxymethyl]-quinoline (PF-2545920) for the treatment of schizophrenia. J Med Chem. 2009; 52:5188-5196. [PubMed: 19630403]

46. Bender A, Beavo J. Cyclic nucleotide phosphodiesterases: molecular regulation to clinical use. Pharmacol Rev. 2006; 58:488-520. [PubMed: 16968949]

47. Kranz M, et al. Identification of PDE4B over 4D subtype-selective inhibitors revealing an unprecedented binding mode. Bioorg Med Chem. 2009; 17:5336-5341. [PubMed: 19525117]

48. Huai Q, et al. Enantiomer discrimination illustrated by high resolution crystal structures of type 4 phosphodiesterase. J Med Chem. 2006; 49:1867-1873. [PubMed: 16539372]

49. Wang H, et al. Multiple conformations of phosphodiesterase-5: implications for enzyme function and drug development. J Biol Chem. 2006; 281:21469-21479. This paper reports multiple conformations of the H-loop in the PDE5 catalytic domain, which were induced by the binding of various PDE5 inhibitors. [PubMed: 16735511]

50. Wang H, Ye M, Robinson H, Francis S, Ke H. Conformational variations of both PDE5 and inhibitors provide the structural basis for the physiological effects of vardenafil and sildenafil. Mol Pharmacol. 2008; 73:104-110. [PubMed: 17959709]

51. Brunton L, Hayes J, Mayer S. Functional compartmentation of cyclic AMP and protein kinase in heart. Adv Cycl Nucleotide Res. 1981; 14:391-397.

52. Buxton I, Brunton L. Compartments of cyclic AMP and protein kinase in mammalian cardiomyocytes. J Biol Chem. 1983; 258:10233-10239. This paper shows, for the first time, how cAMP-mediated activation of PKA is compartmentalized and describes an important physiological response associated with this compartmentalization. [PubMed: 6309796] 
53. Bregman D, Bhattacharyya N, Rubin C. High affinity binding protein for the regulatory subunit of cAMP-dependent protein kinase II-B. Cloning, characterization, and expression of cDNAs for rat brain P150. J Biol Chem. 1989; 264:4648-4656. This is the first report regarding the isolation and characterization of an AKAP. [PubMed: 2538452]

54. Bregman D, Hirsch A, Rubin C. Molecular characterization of bovine brain P75, a high affinity binding protein for the regulatory subunit of cAMP-dependent protein kinase II beta. J Biol Chem. 1991; 266:7207-7213. [PubMed: 2016323]

55. Jurevicius J, Fischmeister R. cAMP compartmentation is responsible for a local activation of cardiac $\mathrm{Ca}^{2+}$ channels by $\beta$-adrenergic agonists. Proc Natl Acad Sci USA. 1996; 93:295-299. [PubMed: 8552625]

56. Zaccolo M, et al. A genetically encoded, fluorescent indicator for cyclic AMP in living cells. Nature Cell Biol. 2000; 2:25-29. [PubMed: 10620803]

57. Maurice DH. Subcellular signaling in the endothelium: cyclic nucleotides take their place. Curr Opin Pharmacol. 2011; 11:656-664. [PubMed: 22036169]

58. Stangherlin A, et al. cGMP signals modulate cAMP levels in a compartment-specific manner to regulate catecholamine-dependent signaling in cardiac myocytes. Circ Res. 2011; 108:929-939. [PubMed: 21330599]

59. Mongillo M, et al. Compartmentalized phosphodiesterase- 2 activity blunts $\beta$-adrenergic cardiac inotropy via an NO/cGMP-dependent pathway. Circ Res. 2006; 98:226-234. [PubMed: 16357307]

60. Stangherlin A, Zaccolo M. cGMP-cAMP interplay in cardiac myocytes: a local affair with farreaching consequences for heart function. Biochem Soc Trans. 2012; 40:11-14. [PubMed: 22260658]

61. Dodge-Kafka KL, et al. The protein kinase A anchoring protein mAKAP coordinates two integrated cAMP effector pathways. Nature. 2005; 437:574-578. This paper effectively brings together the importance of AKAPs in coordinating specific subcellular signalling pathways. [PubMed: 16177794]

62. Wilson LS, et al. A phosphodiesterase 3B-based signaling complex integrates exchange protein activated by cAMP 1 (EPAC1) and phosphatidylinositol 3-kinase signals in human arterial endothelial cells. J Biol Chem. 2011; 286:16285-16296. This is the first report of a PDE3B-based, EPAC1-containing signalosome and the demonstration that a peptide disruptor leads to constitutive activation of EPAC1 in human cells. [PubMed: 21393242]

63. Rampersad SN, et al. Cyclic AMP phosphodiesterase 4D (PDE4D) Tethers EPAC1 in a vascular endothelial cadherin (VE-Cad)-based signaling complex and controls cAMP-mediated vascular permeability. J Biol Chem. 2010; 285:33614-33622. [PubMed: 20732872]

64. Terrin A, et al. PKA and PDE4D3 anchoring to AKAP9 provides distinct regulation of cAMP signals at the centrosome. J Cell Biol. 2012; 198:607-621. [PubMed: 22908311]

65. Brown KM, et al. Phosphodiesterase-8A binds to and regulates Raf-1 kinase. Proc Natl Acad Sci USA. 2013; 110:E1533-E1542. [PubMed: 23509299]

66. Conti M. Phosphodiesterases and regulation of female reproductive function. Curr Opin Pharmacol. 2011; 11:665-669. [PubMed: 22019564]

67. Masciarelli S, et al. Cyclic nucleotide phosphodiesterase $3 \mathrm{~A}$-deficient mice as a model of female infertility. J Clin Invest. 2004; 114:196-205. This study shows that $P d e 3 a^{-/-}$mice are infertile because increased cAMP-PKA signalling inhibits oocyte maturation in these mice, as well as their capacity for fertilization. [PubMed: 15254586]

68. Cote, RH. Cyclic Nucleotide Phosphodiesterases in Health and Disease. Beavo, J.; Francis, S.; Houslay, M., editors. CRC Press; 2007. p. 165-194.

69. Hartong DT, Berson EL, Dryja TP. Retinitis pigmentosa. Lancet. 2006; 368:1795-1809. [PubMed: 17113430]

70. Ramamurthy V, Niemi GA, Reh TA, Hurley JB. Leber congenital amaurosis linked to AIPL1: a mouse model reveals destabilization of cGMP phosphodiesterase. Proc Natl Acad Sci USA. 2004; 101:13897-13902. [PubMed: 15365178]

71. Davis RJ, et al. Functional rescue of degenerating photoreceptors in mice homozygous for a hypomorphic cGMP phosphodiesterase6 b allele (Pde6bH620Q). Investig Ophthalmol Vis Sci. 2008; 49:5067-5076. [PubMed: 18658088] 
72. Azzouni F, Abu samra K. Are phosphodiesterase type 5 inhibitors associated with visionthreatening adverse events? A critical analysis and review of the literature. J Sex Med. 2011; 8:2894-2903. [PubMed: 21771280]

73. Gretarsdottir $\mathrm{S}$, et al. The gene encoding phosphodiesterase 4D confers risk of ischemic stroke. Nature Genet. 2003; 35:131-138. [PubMed: 14517540]

74. Labuda M, et al. Phosphodiesterase type 4D gene polymorphism: association with the response to short-acting bronchodilators in paediatric asthma patients. Mediators Inflamm. 2011; 2011:301695. [PubMed: 21876611]

75. Fatemi SH, et al. PDE4B polymorphisms and decreased PDE4B expression are associated with schizophrenia. Schizophr Res. 2008; 101:36-49. [PubMed: 18394866]

76. Tsai LL, Beavo JA. The roles of cyclic nucleotide phosphodiesterases (PDEs) in steroidogenesis. Curr Opin Pharmacol. 2011; 11:670-675. [PubMed: 21962440]

77. Shimizu-albergine M, Tsai LL, Patrucco E, Beavo JA. cAMP-specific phosphodieterases 8A and 8B, essential regulators of Leydig cell steroidogenesis. Mol Pharmacol. 2012; 81:556-566. [PubMed: 22232524]

78. Horvath A, Mericq V, Stratakis CA. Mutation in PDE8B, a cyclic AMP-specific phosphodiesterase, in adrenal hyperplasia. N Engl J Med. 2008; 358:750-752. [PubMed: 18272904]

79. Rothenbuhler A, et al. Identification of novel genetic variants in phosphodiesterase 8B (PDE8B), a cAMP-specific phosphodiesterase highly expressed in the adrenal cortex, in a cohort of patients with adrenal tumours. Clin Endocrinol. 2012; 77:195-199.

80. Horvath A, et al. A genome-wide scan identifies mutations in the gene encoding phosphodiesterase 11A4 (PDE11A) in individuals with adrenocortical hyperplasia. Nature Genet. 2006; 38:794-800. This paper reports that inactivating mutations in PDE11A increase cAMP levels of affected individuals, leading to aberrant cAMP signalling, which can be associated with the development of adrenocortical hyperplasia. [PubMed: 16767104]

81. Levy I, Horvath A, Azevedo M, de Alexandre RB, Stratakis CA. Phosphodiesterase function and endocrine cells: links to human disease and roles in tumor development and treatment. Curr Opin Pharmacol. 2011; 11:689-697. [PubMed: 22047791]

82. Libé R, et al. Frequent phosphodiesterase 11A gene (PDE11A) defects in patients with Carney complex (CNC) caused by PRKAR1A mutations: PDE11A may contribute to adrenal and testicular tumors in CNC as a modifier of the phenotype. J Clin Endocrinol Metab. 2011; 96:E208-E214. [PubMed: 21047926]

83. Savai R, et al. Targeting cancer with phosphodiesterase inhibitors. Expert Opin Investig Drugs. 2010; 19:117-131.

84. Zhang L, et al. Cyclic nucleotide phosphodiesterase 7B mRNA: an unfavorable characteristic in chronic lymphocytic leukemia. Int J Cancer. 2011; 129:1162-1169. [PubMed: 21120911]

85. Zhang L, et al. Cyclic nucleotide phosphodiesterase profiling reveals increased expression of phosphodiesterase 7B in chronic lymphocytic leukemia. Proc Natl Acad Sci USA. 2008; 105:19532-19537. [PubMed: 19033455]

86. Lin D, et al. Genomic and functional characterizations of phosphodiesterase subtype 4D in human cancers. Proc Natl Acad Sci USA. 2013; 110:6109-6114. [PubMed: 23536305]

87. Pullamsetti SS, et al. Phosphodiesterase-4 promotes proliferation and angiogenesis of lung cancer by crosstalk with HIF. Oncogene. 2013; 32:1121-1134. [PubMed: 22525277]

88. Almeida MQ, Stratakis CA. How does cAMP/protein kinase A signaling lead to tumors in the adrenal cortex and other tissues? Mol Cell Endocrinol. 2011; 336:162-168. [PubMed: 21111774]

89. Yamanaka D, et al. Phosphatidylinositol 3-kinase-binding protein, PI3KAP/XB130, is required for cAMP-induced amplification of IGF mitogenic activity in FRTL-5 thyroid cells. Mol Endocrinol. 2012; 26:1043-1055. [PubMed: 22496359]

90. Black KL, et al. PDE5 inhibitors enhance tumor permeability and efficacy of chemotherapy in a rat brain tumor model. Brain Res. 2008; 1230:290-302. [PubMed: 18674521]

91. Wachtel H. Potential antidepressant effects of rolipram and other selective PDE inhibitors. Neuropharmacol. 1983; 22:267-272. 
92. Houslay MD, Schafer P, Zhang KYJ. Phosphodiesterase-4 as a therapeutic target: preclinical and clinical pharmacology. Drug Discov Today. 2005; 10:1503-1519. [PubMed: 16257373]

93. Kelly M, Brandon N. Differential function of phosphodiesterase families in the brain: gaining insights through the use of genetically modified animals. Prog Brain Res. 2009; 179:67-73. [PubMed: 20302819]

94. Clapcote SJ, et al. Behavioral phenotypes of Disc1 missense mutations in mice. Neuron. 2007; 54:387-402. [PubMed: 17481393]

95. Millar JK, et al. Disrupted in schizophrenia 1 and phosphodiesterase 4B: towards an understanding of psychiatric illness. J Physiol. 2007; 584:401-405. [PubMed: 17823207]

96. DeMarch Z, et al. Beneficial effects of rolipram in the R6/2 mouse model of Huntington's disease. Neurobiol Dis. 2008; 30:375-387. [PubMed: 18424161]

97. Giampà $\mathrm{C}$, et al. Inhibition of the striatal specific phosphodiesterase PDE10A ameliorates striatal and cortical pathology in R6/2 mouse model of Huntington's disease. PloS ONE. 2010; 5:e13417. [PubMed: 20976216]

98. Movsesian MA, Kukreja RC. PDE inhibition in heart failure. Handb Exp Pharmacol. 2011; 204:237-250. [PubMed: 21695643]

99. Packer M, et al. Effects of oral milrinone on mortality in severe chronic heart failure. N Engl J Med. 1991; 325:1468-1475. [PubMed: 1944425]

100. Kambayashi, J.; Shakur, Y.; Liu, Y. Cyclic Nucleotide Phosphodiesterases in Health and Disease. Beavo, J.; Francis, S.; Houslay, M., editors. CRC Press; 2007. p. 627-648.

101. Kanlop N, Chattipakorn S, Chattipakorn N. Effects of cilostazol in the heart. J Cardiovasc Med. 2011; 12:88-95.

102. Kukreja RC, et al. Emerging new uses of phosphodiesterase-5 inhibitors in cardiovascular diseases. Exp Clin Cardiol. 2011; 16:e30-e35. [PubMed: 22131856]

103. Archer SL, Michelakis ED. Phosphodiesterase type 5 inhibitors for pulmonary arterial hypertension. N Engl J Med. 2009; 361:1864-1871. [PubMed: 19890129]

104. Schaper W. Dipyridamole, an underestimated vascular protective drug. Cardiovasc Drugs Ther. 2005; 19:357-363. [PubMed: 16382298]

105. Chan S, Yan C. PDE1 isozymes, key regulators of pathological vascular remodeling. Curr Opin Pharmaco. 2011; 11:720-724.

106. Miller CL, et al. Role of $\mathrm{Ca}^{2+} /$ calmodulin-stimulated cyclic nucleotide phosphodiesterase 1 in mediating cardiomyocyte hypertrophy. Circ Res. 2009; 105:956-964. [PubMed: 19797176]

107. Shakur Y, et al. Comparison of the effects of cilostazol and milrinone on cAMP-PDE activity, intracellular cAMP and calcium in the heart. Cardiovasc Drugs Ther. 2002; 16:417-427. [PubMed: 12652111]

108. Toque HA, et al. Vardenafil, but not sildenafil or tadalafil, has calcium-channel blocking activity in rabbit isolated pulmonary artery and human washed platelets. Br J Pharmacol. 2008; 154:787_ 796. [PubMed: 18536732]

109. Shi Z, et al. Sildenafil reverses ABCB1- and ABCG2-mediated chemotherapeutic drug resistance. Cancer Res. 2011; 71:3029-3041. [PubMed: 21402712]

110. Shi Z, Tiwari AK, Patel AS, Fu L, Chen Z. Roles of sildenafil in enhancing drug sensitivity in cancer. Cancer Res. 2011; 71:3735-3738. [PubMed: 21610107]

111. Barnes PJ. Biochemical basis of asthma therapy. J Biol Chem. 2011; 286:32899-32905. [PubMed: 21799015]

112. Yougbaré I, et al. NCS 613 exhibits anti-inflammatory effects on PBMCs from lupus patients by inhibiting p38 MAPK and NFK-B signalling pathways while reducing proinflammatory cytokine production. Can J Physiol Pharmacol. 2013; 91:353-361. [PubMed: 23656347]

113. Minguet $\mathrm{S}$, et al. Adenosine and cAMP are potent inhibitors of the NF- $\kappa \mathrm{B}$ pathway downstream of immunoreceptors. Eur J Immunol. 2005; 35:31-41. [PubMed: 15580656]

114. Saito T, et al. Phosphodiesterase inhibitors suppress Lactobacillus casei cell-wall-induced NF- $\kappa \mathrm{B}$ and MAPK activations and cell proliferation through protein kinase A-or exchange protein activated by cAMP-dependent signal pathways. Scientific World Journal. 2012; 2012:748572. [PubMed: 22645447] 
115. To Y, et al. Targeting phosphoinositide-3-kinase- $\delta$ with theophylline reverses corticosteroid insensitivity in chronic obstructive pulmonary disease. Am J Respir Crit Care Med. 2010; 182:897-904. [PubMed: 20224070]

116. Douglas JJ, et al. Coronary stent restenosis in patients treated with cilostazol. Circulation. 2005; 112:2826-2832. [PubMed: 16246948]

117. Tamhane U, et al. Efficacy of cilostazol in reducing restenosis in patients undergoing contemporary stent based PCI: a meta-analysis of randomised controlled trials. EuroIntervention. 2009; 5:384-393. [PubMed: 19736165]

118. Geng D, et al. Cilostazol-based triple antiplatelet therapy compared to dual antiplatelet therapy in patients with coronary stent implantation: a meta-analysis of 5,821 patients. Cardiology. 2012; 122:148-157. [PubMed: 22832561]

119. Geng D, Deng J, Jin D, Wu W, Wang J. Effect of cilostazol on the progression of carotid intimamedia thickness: a meta-analysis of randomized controlled trials. Atherosclerosis. 2012; 220:177-183. [PubMed: 22015232]

120. Katakami N, Kim Y, Kawamori R, Yamasaki Y. The phosphodiesterase inhibitor cilostazol induces regression of carotid atherosclerosis in subjects with type 2 diabetes mellitus: principal results of the Diabetic Atherosclerosis Prevention by Cilostazol (DAPC) study: a randomized trial. Circulation. 2010; 121:2584-2591. [PubMed: 20516379]

121. Begum N, Hockman S, Manganiello VC. Phosphodiesterase 3A (PDE3A) deletion suppresses proliferation of cultured murine vascular smooth muscle cells (VSMCs) via inhibition of mitogen-activated protein kinase (MAPK) signaling and alterations in critical cell cycle regulatory proteins. J Biol Chem. 2011; 286:26238-26249. [PubMed: 21632535]

122. Keravis T, et al. Disease progression in MRL/lpr lupus-prone mice is reduced by NCS 613, a specific cyclic nucleotide phosphodiesterase type 4 (PDE4) inhibitor. PLoS ONE. 2012; 7:e28899. [PubMed: 22247763]

123. Wittmann M, Helliwell PS. Phosphodiesterase 4 inhibition in the treatment of psoriasis, psoriatic arthritis and other chronic inflammatory diseases. Dermatol Ther. 2013; 3:1-15.

124. Jin S, Conti M. Induction of the cyclic nucleotide phosphodiesterase PDE4B is essential for LPSactivated TNF-a responses. Proc Natl Acad Sci USA. 2002; 99:7628-7633. [PubMed: 12032334]

125. Ariga M, et al. Nonredundant function of Phosphodiesterases 4D and 4B in neutrophil recruitment to the site of inflammation. J Immunol. 2004; 173:7531-7538. [PubMed: 15585880]

126. Hansen G, Jin S, Umetsu DT, Conti M. Absence of muscarinic cholinergic airway responses in mice deficient in the cyclic nucleotide phosphodiesterase PDE4D. Proc Natl Acad Sci USA. 2000; 97:6751-6756. [PubMed: 10841571]

127. Robichaud A, et al. Deletion of phosphodiesterase 4D in mice shortens $a_{2}$-adrenoceptor-mediated anesthesia, a behavioral correlate of emesis. J Clin Invest. 2002; 110:1045-1052. [PubMed: 12370283]

128. Chung JH, Manganiello V, Dyck JRB. Resveratrol as a calorie restriction mimetic: therapeutic implications. Trends Cell Biol. 2012; 22:546-554. [PubMed: 22885100]

129. Park $S$, et al. Resveratrol ameliorates aging-related metabolic phenotypes by inhibiting cAMP phosphodiesterases. Cell. 2012; 148:421-433. This paper demonstrates that the metabolic effects of resveratrol may be mediated by PDE4 inhibition. [PubMed: 22304913]

130. Zhang R, Maratos-Flier E, Flier JS. Reduced adiposity and high-fat diet-induced adipose inflammation in mice deficient for phosphodiesterase 4B. Endocrinology. 2009; 150:3076-3082. [PubMed: 19359377]

131. Wouters E, et al. Effect of the phosphodiesterase 4 inhibitor roflumilast on glucose metabolism in patients with treatment-naive, newly diagnosed type 2 diabetes mellitus. J Clin Endocrinol Metab. 2012; 97:E1720-E1725. This paper demonstrates that the PDE4 inhibitor roflumilast has an antidiabetic effect. [PubMed: 22723325]

132. Lugnier C. PDE inhibitors: a new approach to treat metabolic syndrome? Curr Opin Pharmacol. 2011; 11:698-706. [PubMed: 22018840]

133. Hotamisligil GS. Inflammation and metabolic disorders. Nature. 2006; 444:860-867. [PubMed: 17167474] 
134. Adamo CM, et al. Sildenafil reverses cardiac dysfunction in the mdx mouse model of Duchenne muscular dystrophy. Proc Natl Acad Sci USA. 2010; 107:19079-19083. [PubMed: 20956307]

135. Kass DA. Cardiac role of cyclic-GMP hydrolyzing phosphodiesterase type 5: from experimental models to clinical trials. Curr Heart Fail Rep. 2012; 9:192-199. [PubMed: 22798047]

136. Blanton R, et al. Protein kinase $1 \mathrm{Ga}$ inhibits pressure overload-induced cardiac remodeling and is required for the cardioprotective effect of sildenafil in vivo. J Am Heart Assoc. 2012; 1:e003731. [PubMed: 23316302]

137. Blokland A, Menniti F, Prikaerts J. PDE inhibition and cognition enhancement. Exp Opin Ther Pat. 2012; 22:349-354.

138. Kehler J, Nielsen J. PDE10A Inhibitors: novel therapeutic drugs for schizophrenia. Curr Pharm Des. 2011; 17:137-150. [PubMed: 21355834]

139. Grauer S, et al. Phosphodiesterase 10A inhibitor activity in preclinical models of the positive, cognitive, and negative symptoms of schizophrenia. J Pharmacol Exp Ther. 2009; 331:574-590. [PubMed: 19661377]

140. IntraCellular Therapies and Takeda to develop PDE1 inhibitors for schizophrenia. Nature Rev Drug Discov. 2011; 10:329. No authors listed. [PubMed: 21532553]

141. Kleiman R, et al. Chronic suppression of phosphodiesterase 10A alters striatal expression of genes responsible for neurotransmitter synthesis, neurotransmission, and signaling pathways implicated in Huntington's disease. J Pharmacol Exp Ther. 2011; 336:64-76. [PubMed: 20923867]

142. Loukides S, Bartziokas K, Vestbo JR, Singh D. Novel anti-inflammatory agents in COPD: targeting lung and systemic inflammation. Curr Drug Targets. 2013; 14:235-245. [PubMed: 23256720]

143. Giembycz MA, Newton R. Harnessing the clinical efficacy of phosphodiesterase 4 inhibitors in inflammatory lung diseases: dual-selective PDE inhibitors and novel combination therapies. Handb Exp Pharmacol. 2011; 204:415-446. [PubMed: 21695651]

144. Smith SJ, et al. Discovery of BRL 50481 [3-( $N, N$-dimethylsulfonamido)-4-methyl-nitrobenzene], a selective inhibitor of phosphodiesterase 7: in vitro studies in human monocytes, lung macrophages, and CD8 ${ }^{+}$T-lymphocytes. Mol Pharmacol. 2004; 66:1679-1689. [PubMed: 15371556]

145. Page CP, Spina D. Selective PDE inhibitors as novel treatments for respiratory diseases. Curr Opin Pharmacol. 2012; 12:275-286. [PubMed: 22497841]

146. Fan C. Phosphodiesterase inhibitors in airway disease. Eur J Pharmacol. 2006; 533:110-117. [PubMed: 16458289]

147. Thompson P, Manganiello V, Degerman E. Re-discovering PDE3 Inhibitors: new opportunities for a long neglected target. Curr Top Med Chem. 2007; 7:421-436. [PubMed: 17305583]

148. Mak G, Hanania NA. New bronchodilators. Curr Opin Pharmacol. 2012; 12:238-245. [PubMed: 22445544]

149. Banner K, Press N. Dual PDE3/PDE4 inhibitors as therapeutic agents for chronic obstructive pulmonary disease. Br J Pharmacol. 2009; 157:892-906. [PubMed: 19508401]

150. Foster RW, Rakshi K, Carpenter JR, Small RC. Trials of the bronchodilator activity of the isoenzyme-selective phosphodiesterase inhibitor AH 21-132 in healthy volunteers during a methacholine challenge test. Br J Clin Pharmacol. 1992; 34:527-534. [PubMed: 1493085]

151. Calzetta L, et al. The effect of the mixed Phosphodiesterase 3/4 inhibitor RPL554 on human isolated bronchial smooth muscle tone. J Pharmacol Exp Ther. 2013; 346:414-423. [PubMed: 23766543]

152. Singh D, Petavy F, Macdonald AJ, Lazaar AL, O'Connor BJ. The inhaled phosphodiesterase 4 inhibitor GSK256066 reduces allergen challenge responses in asthma. Resp Res. 2010; 11:26.

153. Pawson CT, Scott JD. Signal integration through blending, bolstering, and bifurcating of intracellular information. Nature Struct Mol Biol. 2010; 17:653-658. [PubMed: 20495562]

154. Wells J, McClendon C. Reaching for high-hanging fruit in drug discovery at protein-protein interfaces. Nature. 2007; 450:1001-1009. [PubMed: 18075579] 
155. Christian F, et al. Small molecule AKAP-protein kinase A (PKA) interaction disruptors that activate PKA interfere with compartmentalized cAMP signaling in cardiac myocytes. J Biol Chem. 2011; 286:9079-9096. [PubMed: 21177871]

156. Keravis T, Lugnier C. Cyclic nucleotide phosphodiesterases (PDEs) and peptide motifs. Curr Pharm Des. 2010; 16:1114-1125. [PubMed: 20030615]

157. Serrels B, et al. A complex between FAK, RACK1, and PDE4D5 controls spreading initiation and cancer cell polarity. Curr Biol. 2010; 20:1086-1092. [PubMed: 20493699]

158. Perry S, et al. Targeting of cyclic AMP degradation to $\beta_{2}$-adrenergic receptors by $\beta$-arrestins. Science. 2002; 298:834-836. [PubMed: 12399592]

159. Yarwood SJ, Steele MR, Scotland G, Houslay MD, Bolger GB. The RACK1 signaling scaffold protein selectively interacts with the cAMP-specific phosphodiesterase PDE4D5 isoform. J Biol Chem. 1999; 274:14909-14917. [PubMed: 10329691]

160. Craik D, Fairlie D, Liras S, Price D. The future of peptide-based drugs. Chem Biol Drug Des. 2013; 81:136-147. [PubMed: 23253135]

161. Sin YY, et al. Disruption of the cyclic AMP phosphodiesterase-4 (PDE4)-HSP20 complex attenuates the $\beta$-agonist induced hypertrophic response in cardiac myocytes. J Mol Cell Cardiol. 2011; 50:872-883. [PubMed: 21334344]

162. Jin SC, et al. Phosphodiesterase 4B is essential for $\mathrm{T}_{\mathrm{H}} 2$-cell function and development of airway hyperresponsiveness in allergic asthma. J Allergy Clin Immunol. 2010; 126:1252-1259. [PubMed: 21047676]

163. Houslay MD, Adams DR. Putting the lid on phosphodiesterase 4. Nature Biotech. 2010; 28:3840.

164. Wang H, Robinson H, Ke H. Conformation changes, N-terminal involvement, and cGMP signal relay in the phosphodiesterase-5 GAF domain. J Biol Chem. 2010; 285:38149-38156. [PubMed: 20861010]

165. Schultz JE, et al. The GAF-tandem domain of PDE5 as a potential drug target. Handb Exp Pharmacol. 2011; 204:151-167. [PubMed: 21695639]

166. Bers D. Cardiac excitation-contraction coupling. Nature. 2002; 415:195-205.

167. Leroy J, Richter W, Mika D. Phosphodiesterase 4B in the cardiac L-type $\mathrm{Ca}^{2+}$ channel complex regulates $\mathrm{Ca}^{2+}$ current and protects against ventricular arrhythmias in mice. J Clin Investig. 2011; 121:2651-2661. [PubMed: 21670503]

168. Lehnart SE, et al. Phosphodiesterase 4D deficiency in the ryanodine-receptor complex promotes heart failure and arrhythmias. Cell. 2005; 123:25-35. [PubMed: 16213210]

169. Beca S, et al. Phosphodiesterase type $3 \mathrm{~A}$ regulates basal myocardial contractility through interacting with sarcoplasmic reticulum calcium ATPase type 2a signaling complexes in mouse heart. Circ Res. 2013; 112:289-297. This study shows that PDE3A, and not PDE3B, is the primary PDE3 isozyme that modulates basal contractility and calcium content of the sarcoplasmic reticulum by regulating cAMP concentrations in microdomains containing macromolecular complexes (signalosomes) composed of AKAP18, sarcoplasmic/endoplasmic reticulum calcium ATPase 2 (SERCA2), phospholamban and PDE3A. [PubMed: 23168336]

170. Kerfant B, et al. PI3K $\gamma$ is required for PDE4, not PDE3, activity in subcellular microdomains containing the sarcoplasmic reticular calcium ATPase in cardiomyocytes. Circ Res. 2007; 101:400-408. [PubMed: 17615371]

171. Ghigo A, et al. Phosphoinositide 3-kinase $\gamma$ protects against catecholamine-induced ventricular arrhythmia through protein kinase A-mediated regulation of distinct phosphodiesterases. Circulation. 2012; 126:2073-2083. [PubMed: 23008439]

172. Molina CE, et al. Cyclic adenosine monophosphate phosphodiesterase type 4 protects against atrial arrhythmias. J Am Coll Cardiol. 2012; 59:2182-2190. [PubMed: 22676938]

173. Molenaar P, et al. PDE3, but not PDE4, reduces $\beta_{1^{-}}$and $\beta_{2}$-adrenoceptor-mediated inotropic and lusitropic effects in failing ventricle from metoprolol-treated patients. Br J Pharmacol. 2013; 169:528-538. [PubMed: 23489141]

174. Siuciak JA, et al. Behavioral and neurochemical characterization of mice deficient in the phosphodiesterase-1B (PDE1B) enzyme. Neuropharmacology. 2007; 53:113-124. [PubMed: 17559891] 
175. Cygnar K, Zhao H. Phosphodiesterase $1 \mathrm{C}$ is dispensable for rapid response termination of olfactory sensory neurons. Nature Neurosci. 2009; 12:454-462. [PubMed: 19305400]

176. Guirguis E, et al. A Role for phosphodiesterase 3B in acquisition of brown fat characteristics by white adipose tissue in male mice. Endocrinology. 2013; 154:1-18. [PubMed: 23267049]

177. Jin S, Lan L, Zoudilova M, Conti M. Specific role of phosphodiesterase 4B in lipopolysaccharideinduced signaling in mouse macrophages. J Immunol. 2005; 175:1523-1531. [PubMed: 16034090]

178. Yang G, et al. Phosphodiesterase 7A-deficient mice have functional T cells. J Immunol. 2003; 171:6414-6420. [PubMed: 14662840]

179. Patrucco E, Albergine MS, Santana LF, Beavo JA. Phosphodiesterase 8A (PDE8A) regulates excitation contraction coupling in ventricular myocytes. J Mol Cell Cardiol. 2010; 49:330-333. [PubMed: 20353794]

180. Tsai LL, et al. Inactivation of Pde8b enhances memory, motor performance, and protects against age-induced motor coordination decay. Genes Brain Behav. 2012; 11:837-847. [PubMed: 22925203]

181. Deninno MP, et al. The discovery of potent, selective, and orally bioavailable PDE9 inhibitors as potential hypoglycemic agents. Bioorg Med Chem Lett. 2009; 19:2537-2541. [PubMed: 19339180]

182. Menniti F, Kleiman R, Schmidt C. PDE9A-mediated regulation of cGMP: Impact on synaptic plasticity. Schizophrenia Research. 2008; 102(Suppl 2):38-39.

183. Seeger TF, et al. Immunohistochemical localization of PDE10A in the rat brain. Brain Res. 2003; 985:113-126. [PubMed: 12967715]

184. Piccart E, et al. Impaired appetitively as well as aversively motivated behaviors and learning in PDE10A-deficient mice suggest a role for striatal signaling in evaluative salience attribution. Neurobiol Learn Mem. 2011; 95:260-269. [PubMed: 21130175]

185. Loughney K, Taylor J, Florio VA. 3',5'-cyclic nucleotide phosphodiesterase 11A: localization in human tissues. Int J Impot Res. 2005; 17:320-325. [PubMed: 15800651]

186. Kelly MP, et al. Phosphodiesterase 11A in brain is enriched in ventral hippocampus and deletion causes psychiatric disease-related phenotypes. Proc Natl Acad Sci USA. 2010; 107:8457-8462. [PubMed: 20404172]

187. Johnson WB, Katugampola S, Able S, Napier C, Harding SE. Profiling of cAMP and cGMP phosphodiesterases in isolated ventricular cardiomyocytes from human hearts: comparison with rat and guinea pig. Life Sci. 2012; 90:328-336. [PubMed: 22261303]

188. Nagel DDJ, et al. Role of nuclear $\mathrm{Ca}^{2+} /$ calmodulin-stimulated phosphodiesterase $1 \mathrm{~A}$ in vascular smooth muscle cell growth and survival. Circulation. 2006; 98:777-784.

189. Jiang X, Li J, Paskind M, Epstein PM. Inhibition of calmodulin-dependent phosphodiesterase induces apoptosis in human leukemic cells. Proc Natl Acad Sci USA. 1996; 93:11236-11241. [PubMed: 8855339]

190. Fisch JD, Behr B, Conti M. Enhancement of motility and acrosome reaction in human spermatozoa: differential activation by type-specific phosphodiesterase inhibitors. Hum Reprod. 1998; 13:1248-1254. [PubMed: 9647555]

191. Laddha SS, Bhatnagar SP. A new therapeutic approach in Parkinson's disease: some novel quinazoline derivatives as dual selective phosphodiesterase 1 inhibitors and anti-inflammatory agents. Bioorg Med Chem. 2009; 17:6796-6802. [PubMed: 19744861]

192. MacFarland RT, Zelus BD, Beavo J. High concentrations of a cGMP-stimulated phosphodiesterase mediate ANP-induced decreases in cAMP and steroidogenesis in adrenal glomerulosa cells. J Biol Chem. 1991; 266:136-142. [PubMed: 1845962]

193. Favot L, Keravis T, Holl V, Le Bec A, Lugnier C. VEGF-induced HUVEC migration and proliferation are decreased by PDE2 and PDE4 inhibitors. Thromb Haemost. 2003; 90:334-343. [PubMed: 12888882]

194. Surapisitchat J, Jeon K, Yan C, Beavo J. Differential regulation of endothelial cell permeability by cGMP via phosphodiesterases 2 and 3. Circ Res. 2007; 101:811-818. [PubMed: 17704206]

195. Dickinson N, Jang E, Haslam R. cAMP accumulation in human platelets: effects on platelet aggregation. Biochem J. 1997; 377:371-377. [PubMed: 9163326] 
196. Reneerkens O, et al. Selective phosphodiesterase inhibitors: a promising target for cognition enhancement. Psychopharmacology. 2009; 202:419-443. [PubMed: 18709359]

197. Hambleton R, et al. Isoforms of cyclic nucleotide phosphodiesterase PDE3 and their contribution to cAMP hydrolytic activity in subcellular fractions of human myocardium. J Biol Chem. 2005; 280:39168-39174. [PubMed: 16172121]

198. Oikawa M, et al. Cyclic nucleotide phosphodiesterase $3 \mathrm{~A} 1$ protects the heart against ischemiareperfusion injury. J Mol Cell Cardiol. 2013; 64:11-19. [PubMed: 23988739]

199. Maurice D, Haslam R. Molecular basis of the synergistic inhibition of platelet function by nitrovasodilators and activators of adenylate cyclase: inhibition of cyclic AMP breakdown by cyclic GMP. Mol Pharmacol. 1990; 37:671-681. [PubMed: 2160060]

200. Zhao A, Huan J, Gupta S, Pal R, Sahu A. A phosphatidylinositol 3-kinase phosphodiesterase 3Bcyclic AMP pathway in hypothalamic action of leptin on feeding. Nature Neurosci. 2002; 5:727728. This report identifies PDE3B as a crucial regulator of feeding behaviour in animals. [PubMed: 12101402]

201. Cheng Y, et al. Inhibition of phosphodiesterase-4 reverses memory deficits produced by A $\beta 25-35$ or A $\beta 1-40$ peptide in rats. Psychopharmacology. 2010; 212:181-191. [PubMed: 20640406]

202. Tralau-Stewart C, Williamson R. GSK256066, an exceptionally high-affinity and selective inhibitor of phosphodiesterase 4 suitable for administration by inhalation: in vitro, kinetic, and in vivo characterization. J Pharmacol Exp Ther. 2011; 337:145-154. [PubMed: 21205923]

203. Bäumer W, et al. AWD 12-281, a highly selective phosphodiesterase 4 inhibitor, is effective in the prevention and treatment of inflammatory reactions in a model of allergic dermatitis. J Pharm Pharmacol. 2003; 55:1107-1114. [PubMed: 12956900]

204. Marko D, et al. Induction of apoptosis by an inhibitor of cAMP-specific PDE in malignant murine carcinoma cells overexpressing PDE activity in comparison to their nonmalignant counterparts. Cell Biochem Biophys. 1998; 28:75-101. [PubMed: 9515161]

205. Reid D, Pham N. Roflumilast: a novel treatment for chronic obstructive pulmonary disease. Ann Pharmacother. 2012; 46:521-529. [PubMed: 22433610]

206. Barnette MS, et al. SB 207499 (Ariflo), a potent and selective second-generation phosphodiesterase 4 inhibitor: in vitro anti-inflammatory actions. J Pharmacol Exp Ther. 1998; 284:420-426. [PubMed: 9435206]

207. Zhu J, Mix E, Winblad B. The antidepressant and antiinflammatory effects of rolipram in the central nervous system. CNS Drug Rev. 2001; 7:387-398. [PubMed: 11830756]

208. Bickston SJ, Snider KR, Kappus MR. Tetomilast: new promise for phosphodiesterase-4 inhibitors? Expert Opin Investig Drugs. 2012; 21:1845-1849.

209. Man H, et al. Discovery of $(S)-N$ - $\{2$-[1-(3-ethoxy-4-methoxyphenyl)-2methanesulfonylethyl]-1,3-dioxo-2,3-dihydro- $1 H$-isoindol-4-yl $\}$ acetamide (apremilast), a potent and orally active phosphodiesterase 4 and tumor necrosis factor-a inhibitor. J Med Chem. 2009; 52:1522-1524. [PubMed: 19256507]

210. Kuang R, et al. Discovery of oxazole-based PDE4 inhibitors with picomolar potency. Bioorg Med Chem Lett. 2012; 22:2594-2597. [PubMed: 22401864]

211. Kotera J, et al. Avanafil, a potent and highly selective phosphodiesterase-5 inhibitor for erectile dysfunction. J Urol. 2012; 188:668-674. [PubMed: 22704456]

212. Andersson K, de Groat W. Tadalafil for the treatment of lower urinary tract symptoms secondary to benign prostatic hyperplasia: pathophysiology and mechanism (s) of action. Neurourol Urodyn. 2011; 30:292-301. [PubMed: 21284024]

213. Oh T, Kang K, Ahn B, Yoo M, Kim W. Erectogenic effect of the selective phosphodiesterase type 5 inhibitor, DA-8159. Arch Pharmacol Res. 2000; 23:471-476.

214. Jung J, et al. The penile erection efficacy of a new phosphodiesterase type 5 inhibitor, mirodenafil (SK3530), in rabbits with acute spinal cord injury. J Vet Med Sci. 2008; 70:1199-1204. [PubMed: 19057138]

215. Galie N, et al. Sildenafil citrate therapy for pulmonary arterial hypertension. N Engl J Med. 2005; 353:2148-2157. [PubMed: 16291984] 
216. Kadoshima-Yamaoka K, et al. ASB16165, a novel inhibitor for phosphodiesterase 7A (PDE7A), suppresses IL-12-induced IFN- $\gamma$ production by mouse activated T lymphocytes. Immunol Lett. 2009; 122:193-197. [PubMed: 19195485]

217. Banerjee A, et al. Imidazopyridazinones as novel PDE7 inhibitors: SAR and in vivo studies in Parkinson's disease model. Bioorg Med Chem Lett. 2012; 22:6286-6291. [PubMed: 22944118]

218. Dong H, Osmanova V, Epstein PM, Brocke S. Phosphodiesterase 8 (PDE8) regulates chemotaxis of activated lymphocytes. Biochem Biophys Res Commun. 2006; 345:713-719. [PubMed: 16696947]

219. Liddie S, Anderson KL, Paz A, Itzhak Y. The effect of phosphodiesterase inhibitors on the extinction of cocaine-induced conditioned place preference in mice. J Psychopharmacol. 2012; 26:1375-1382. [PubMed: 22596207]

220. Saravani R, Karami-Tehrani F, Hashemi M, Aghaei M, Edalat R. Inhibition of phosphodiestrase 9 induces cGMP accumulation and apoptosis in human breast cancer cell lines, MCF-7 and MDAMB-468. Cell Prolif. 2012; 45:199-206. [PubMed: 22469131]

221. Wunder F, Tersteegen A, Rebmann A. Characterization of the first potent and selective PDE9 inhibitor using a cGMP reporter cell line. Mol Pharmacol. 2005; 68:1775-1781. [PubMed: 16150925]

222. Hutson PH, et al. The selective phosphodiesterase 9 (PDE9) inhibitor PF-04447943 (6-[(3S, 4S)-4-methyl-1-(pyrimidin-2-ylmethyl)pyrrolidin-3-yl]-1-(tetrahydro-2H-pyran-4-yl)-1,5dihydro-4H-pyrazolo [3,4-d]pyrimidin-4-one) enhances synaptic plasticity and cognitive function in rodents. Neuropharmacology. 2011; 61:665-676. [PubMed: 21619887]

223. Tian X, et al. Phosphodiesterase 10A upregulation contributes to pulmonary vascular remodeling. PLoS ONE. 2011; 6:e18136. [PubMed: 21494592]

224. Helal CJ, et al. Use of structure-based design to discover a potent, selective, in vivo active phosphodiesterase 10A inhibitor lead series for the treatment of schizophrenia. J Med Chem. 2011; 54:4536-4547. [PubMed: 21650160]

225. Hu E, Ma J, Biorn C. Rapid identification of a novel small molecule phosphodiesterase 10A (PDE10A) tracer. J Med Chem. 2012; 55:4776-4787. [PubMed: 22548439]

226. Rzasa RM, et al. Discovery of selective biaryl ethers as PDE10A inhibitors: improvement in potency and mitigation of Pgp-mediated efflux. Bioorg Med Chem Lett. 2012; 22:7371-7375. [PubMed: 23149228]

227. Bauer U, et al. Discovery of 4-hydroxy-1,6-naphthyridine-3-carbonitrile derivatives as novel PDE10A inhibitors. Bioorg Med Chem Lett. 2012; 22:1944-1948. [PubMed: 22321214]

228. Hofgen N, et al. Discovery of imidazo[1,5-a] pyrido[3,2-e]pyrazines as a new class of phosphodiesterase 10A inhibitiors. J Med Chem. 2010; 53:4399-4411. [PubMed: 20450197]

229. Cutshall NS, et al. Novel 2-methoxyacylhydrazones as potent, selective PDE10A inhibitors with activity in animal models of schizophrenia. Bioorg Med Chem Lett. 2012; 22:5595-5599. [PubMed: 22841436]

230. Francis SH. Phosphodiesterase 11 (PDE11): is it a player in human testicular function? Int J Impot Res. 2005; 17:467-468. [PubMed: 16079899]

231. Wong M, et al. Phosphodiesterase genes are associated with susceptibility to major depression and antidepressant treatment response. Proc Natl Acad Sci USA. 2006; 103:15124-15129. [PubMed: 17008408]

232. Miller CL, et al. Cyclic nucleotide phosphodiesterase 1A: a key regulator of cardiac fibroblast activation and extracellular matrix remodeling in the heart. Bas Res Cardiol. 2011; 106:10231039.

233. Cai Y, et al. Cyclic nucleotide phosphodiesterase 1 regulates lysosome-dependent type I collagen protein degradation in vascular smooth muscle cells. Arterioscler Thromb Vasc Biol. 2011; 31:616-623. [PubMed: 21148428]

234. Acin-Perez R, et al. A phosphodiesterase 2A isoform localized to mitochondria regulates respiration. J Biol Chem. 2011; 286:30423-30432. [PubMed: 21724846]

235. Russwurm C, Zoidl G, Koesling D, Russwurm M. Dual acylation of PDE2A splice variant 3: targeting to synaptic membranes. J Biol Chem. 2009; 284:25782-25790. [PubMed: 19632989] 
236. Mohamed TMA, et al. Plasma membrane calcium pump (PMCA4)-neuronal nitric-oxide synthase complex regulates cardiac contractility through modulation of a compartmentalized cyclic nucleotide microdomain. J Biol Chem. 2011; 286:41520-41529. [PubMed: 21965681]

237. Castro LRV, Schittl J, Fischmeister R. Feedback control through cGMP-dependent protein kinase contributes to differential regulation and compartmentation of cGMP in rat cardiac myocytes. Circ Res. 2010; 107:1232-1240. [PubMed: 20847310]

238. Nishioka K, et al. Cilostazol suppresses angiotensin II-induced vasoconstriction via protein kinase A-mediated phosphorylation of the transient receptor potential canonical 6 channel. Arterioscler Thromb Vasc Biol. 2011; 31:2278-2286. [PubMed: 21799177]

239. Puxeddu E, et al. Interaction of phosphodiesterase $3 \mathrm{~A}$ with brefeldin A-inhibited guanine nucleotide-exchange proteins BIG1 and BIG2 and effect on ARF1 activity. Proc Natl Acad Sci USA. 2009; 106:6158-6163. [PubMed: 19332778]

240. Penmatsa H, et al. Compartmentalized cAMP at the plasma membrane clusters PDE3A and cystic fibrosis transmembrane conductance regulator into microdomains. Mol Biol Cell. 2010;

21:1097-1110. [PubMed: 20089840]

241. Pozuelo Rubio M, Campbell DG, Morrice NA, Mackintosh C. Phosphodiesterase 3A binds to 14-3-3 proteins in response to PMA-induced phosphorylation of Ser428. Biochem J. 2005; 392:163-172. [PubMed: 16153182]

242. Palmer D, et al. Protein kinase A phosphorylation of human phosphodiesterase 3B promotes 14-3-3 protein binding and inhibits phosphatase-catalyzed inactivation. J Biol Chem. 2007; 282:9411-9419. [PubMed: 17255105]

243. Ahmad F, et al. Insulin-induced formation of macromolecular complexes involved in activation of cyclic nucleotide phosphodiesterase 3B (PDE3B) and its interaction with PKB. Biochem J. 2007; 404:257-268. This study demonstrates that, in 3T3-L1 adipocytes, insulin-induced phosphorylation and activation of membrane-associated PDE3B is co-ordinated with its incorporation into a signalosome containing components of the insulin signalling pathway. [PubMed: 17324123]

244. Perino A, et al. Integrating cardiac PIP3 and cAMP signaling through a PKA anchoring function of p110 $\gamma$. Mol Cell. 2011; 42:84-95. [PubMed: 21474070]

245. Sachs BD, et al. p75 neurotrophin receptor regulates tissue fibrosis through inhibition of plasminogen activation via a PDE4/cAMP/PKA pathway. J Cell Biol. 2007; 177:1119-1132. [PubMed: 17576803]

246. Christian F, et al. p62 (SQSTM1) and cyclic AMP phosphodiesterase-4A4 (PDE4A4) locate to a novel, reversible protein aggregate with links to autophagy and proteasome degradation pathways. Cell Signal. 2010; 22:1576-1596. [PubMed: 20600853]

247. Huston E, Gall I, Houslay TM, Houslay MD. Helix-1 of the cAMP-specific phosphodiesterase PDE4A1 regulates its phospholipase-D-dependent redistribution in response to release of $\mathrm{Ca}^{2+} \mathrm{J}$ Cell Sci. 2006; 119:3799-3810. [PubMed: 16940352]

248. Bajpai M, et al. AKAP3 selectively binds PDE4A isoforms in bovine spermatozoa. Biol Reprod. 2006; 74:109-118. [PubMed: 16177223]

249. Asirvatham AL, et al. A-kinase anchoring proteins interact with phosphodiesterases in $\mathrm{T}$ lymphocyte cell lines. J Immunol. 2004; 173:4806-4814. [PubMed: 15470020]

250. Mcphee I, et al. Association with the SRC family tyrosyl kinase LYN triggers a conformational change in the catalytic region of human cAMP-specific PDE HSPDE4A4B: consequences for rolipram inhibition. J Biol Chem. 1999; 274:11796-11810. [PubMed: 10206997]

251. Bolger GB, et al. Attenuation of the activity of the cAMP-specific phosphodiesterase PDE4A5 by interaction with the immunophilin XAP2. J Biol Chem. 2003; 278:33351-33363. [PubMed: 12810716]

252. Millar JK, et al. DISC1 and PDE4B are interacting genetic factors in schizophrenia that regulate cAMP signaling. Science. 2005; 310:1187-1191. [PubMed: 16293762]

253. Bradshaw NJ, et al. DISC1, PDE4B, and NDE1 at the centrosome and synapse. Biochem Biophys Res Commun. 2008; 377:1091-1096. [PubMed: 18983980] 
254. Choi YH, et al. Polycystin-2 and phosphodiesterase 4C are components of a ciliary A-kinase anchoring protein complex that is disrupted in cystic kidney diseases. Proc Natl Acad Sci USA. 2011; 108:10679-10684. [PubMed: 21670265]

255. Baillie GS, et al. $\beta$-arrestin-mediated PDE4 cAMP phosphodiesterase recruitment regulates $\beta$ adrenoceptor switching from $G_{s}$ to $G_{i}$. Proc Natl Acad Sci USA. 2003; 100:940-945. This is the first demonstration that a direct interaction between PDE4 and $\beta$-arrestin controls $\beta$-adrenergic receptor-mediated signalling in cells. [PubMed: 12552097]

256. Kim HW, et al. Cyclic AMP controls mTOR through regulation of the dynamic interaction between Rheb and phosphodiesterase 4D. Mol Cell Biol. 2010; 30:5406-5420. [PubMed: 20837708]

257. Verde I, et al. Myomegalin is a novel protein of the Golgi/centrosome that interacts with a cyclic nucleotide phosphodiesterase. J Biol Chem. 2001; 276:11189-11198. [PubMed: 11134006]

258. Beca S, et al. Phosphodiesterase 4D regulates baseline sarcoplasmic reticulum $\mathrm{Ca}^{2+}$ release and cardiac contractility, independently of L-type $\mathrm{Ca}^{2+}$ current. Circ Res. 2011; 109:1024-1030. [PubMed: 21903937]

259. Huo Z, et al. Prolyl hydroxylase domain protein 2 regulates the intracellular cyclic AMP level in cardiomyocytes through its interaction with phosphodiesterase 4D. Biochem Biophys Res Commun. 2012; 427:73-79. [PubMed: 22975349]

260. Stefan E, et al. Compartmentalization of cAMP-dependent signaling by phosphodiesterase-4D is involved in the regulation of vasopressin-mediated water reabsorption in renal principal cells. $\mathbf{J}$ Am Soc Nephrol. 2007; 18:199-212. [PubMed: 17135396]

261. Dodge-Kafka KL, et al. cAMP-stimulated protein phosphatase $2 \mathrm{~A}$ activity associated with muscle A kinase-anchoring protein (mAKAP) signaling complexes inhibits the phosphorylation and activity of the cAMP-specific phosphodiesterase PDE4D3. J Biol Chem. 2010; 285:1107811086. [PubMed: 20106966]

262. Halls ML, Cooper DMF. Sub-picomolar relaxin signalling by a pre-assembled RXFP1, AKAP79, AC2, $\beta$-arrestin 2, PDE4D3 complex. EMBO J. 2010; 29:2772-2787. [PubMed: 20664520]

263. Terrenoire C, Houslay MD, Baillie GS, Kass RS. The cardiac IKs potassium channel macromolecular complex includes the phosphodiesterase PDE4D3. J Biol Chem. 2009; 284:9140-9146. [PubMed: 19218243]

264. Raymond DR, Carter RL, Ward CA, Maurice DH. Distinct phosphodiesterase-4D variants integrate into protein kinase A-based signaling complexes in cardiac and vascular myocytes. Am J Physiol Heart Circ Physiol. 2009; 296:H263-H271. [PubMed: 19060129]

265. Creighton J, Zhu B, Alexeyev M, Stevens T. Spectrin-anchored phosphodiesterase 4D4 restricts cAMP from disrupting microtubules and inducing endothelial cell gap formation. J Cell Sci. 2008; 121:110-119. [PubMed: 18073242]

266. Beard MB, O'Connell JC, Bolger GB, Houslay MD. The unique N-terminal domain of the cAMP phosphodiesterase PDE4D4 allows for interaction with specific SH3 domains. FEBS Lett. 1999; 460:173-177. [PubMed: 10571082]

267. De Arcangelis V, Liu R, Soto D, Xiang Y. Differential association of phosphodiesterase 4D isoforms with $\beta_{2}$-adrenoceptor in cardiac myocytes. J Biol Chem. 2009; 284:33824-33832. [PubMed: 19801680]

268. Richter $W$, et al. Signaling from $\beta_{1}$ - and $\beta_{2}$-adrenergic receptors is defined by differential interactions with PDE4. EMBO J. 2008; 27:384-393. [PubMed: 18188154]

269. Zhang M, et al. Pathological cardiac hypertrophy alters intracellular targeting of phosphodiesterase type 5 from nitric oxide synthase- 3 to natriuretic peptide signaling. Circulation. 2012; 126:942-951. [PubMed: 22829024]

270. Wilson L, Elbatarny H, Crawley S, Bennett B, Maurice DH. Compartmentation and compartment-specific regulation of PDE5 by protein kinase $\mathrm{G}$ allows selective cGMP-mediated regulation of platelet functions. Proc Natl Acad Sci USA. 2008; 105:13650-13655. This is the first report to show that compartmentalization of a PDE - PDE5 - occurs in a cell type (human platelets) in which PDE5 is the sole cGMP-PDE activity present. [PubMed: 18757735] 
271. Han P, Sonati P, Rubin C, Michaeli T. PDE7A1, a cAMP-specific phosphodiesterase, inhibits cAMP-dependent protein kinase by a direct interaction with C. J Biol Chem. 2006; 281:1505015057. [PubMed: 16556600]

272. Wu P, Wang P. Per-Arnt-Sim domain-dependent association of cAMP-phosphodiesterase 8A1 with IkB proteins. Proc Natl Acad Sci USA. 2004; 101:17634-17639. [PubMed: 15596729] 


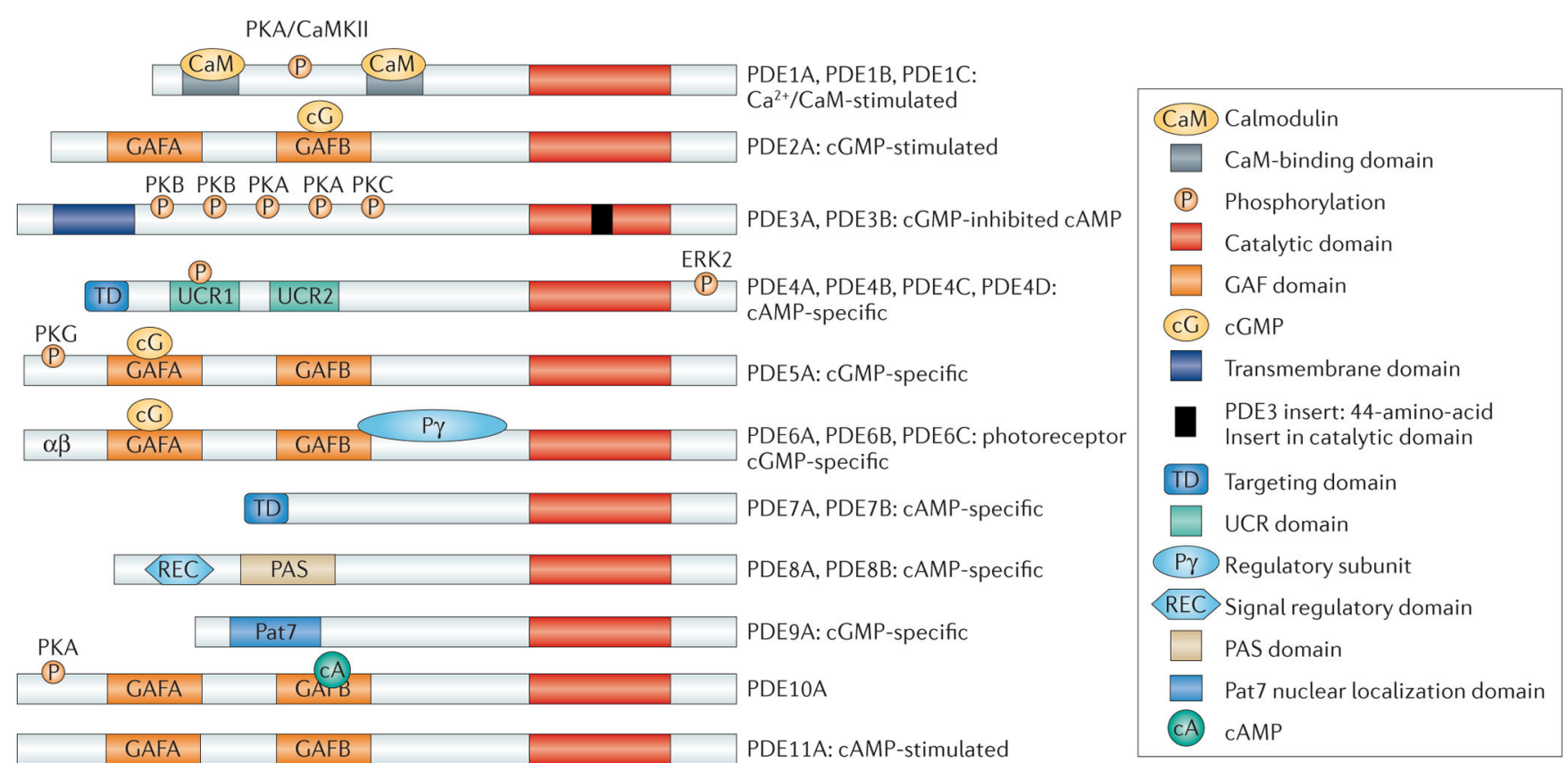

Figure 1. Structure and domain organization of 11 mammalian PDE families

The conserved catalytic domain (shown in red) is located in the carboxy-terminal portion of the phosphodiesterases (PDEs). The catalytic domain of PDE3 contains a unique 44-aminoacid insert (shown in black). Many of the PDE families ${ }^{1-3}$ contain amino-terminal subdomains (such as GAF domains, transmembrane domains, targeting domains, upstream conserved regions (UCRs), PAS domains and REC domains) and N-terminal hydrophobic regions that are important in subcellular localization, in the incorporation of PDEs into compartmentalized signalosomes, in interactions with signalling molecules and molecular scaffolds, and in the regulation of PDE activity. GAF domains regulate the allosteric binding of cGMP (to PDE2, PDE5, PDE6 and PDE11), the allosteric binding of cAMP (to PDE10) and the regulation of catalytic activity (in PDE2, PDE5 and PDE6). Phosphorylation sites are labelled on the figure. CaMKII, calcium/calmodulin-dependent protein kinase II; ERK2, extracellular signal-regulated kinase 2; PKA, protein kinase A; Pat7, 7-residue nuclear localization signal. 

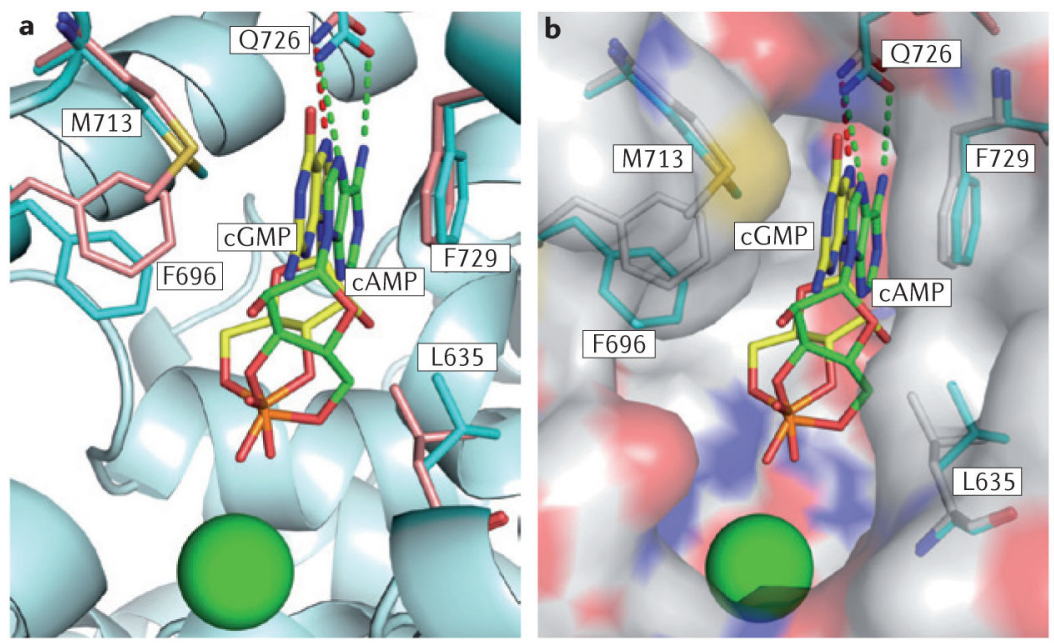

c

d

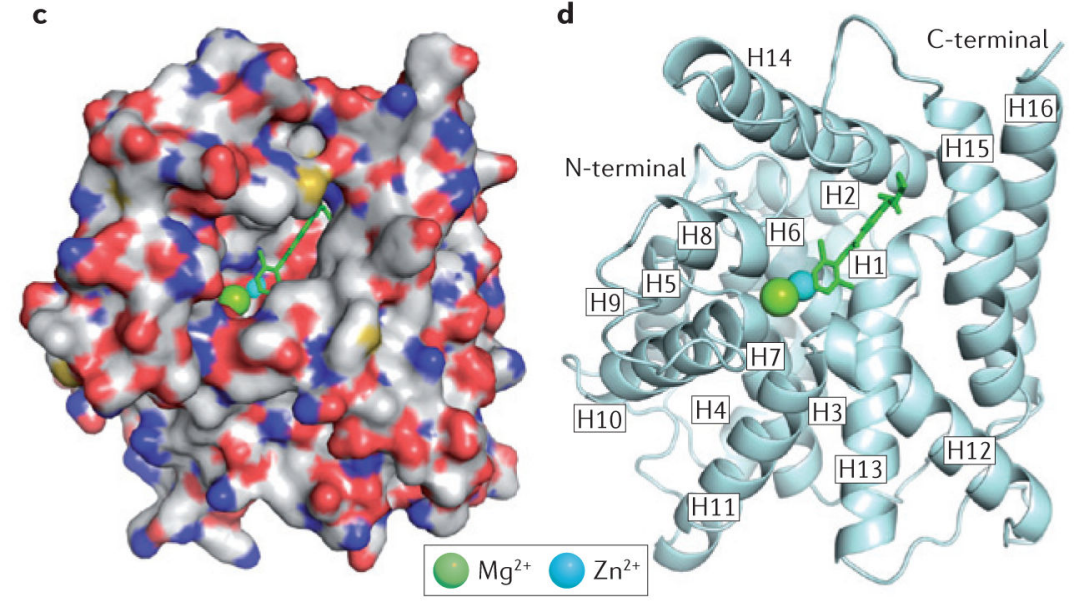

Figure 2. Binding of substrates and inhibitors to the active site of PDEs

a Interaction of the substrates cAMP (green sticks) and cGMP (yellow sticks) with the D674A mutant of phosphodiesterase 10A2 (PDE10A2). Residues from the structures of PDE10A2-cAMP and PDE10A2-cGMP are shown in cyan and pale orange, respectively. Binding to $\mathrm{Zn}^{2+}$ was lost owing to the D674A mutation. Substrates of cAMP and cGMP have the same syn-conformation, but opposite orientations. b | Surface presentation of the binding of cAMP and cGMP to the D674A mutant of PDE10A2. c | Surface presentation of PDE4D2 binding to roflumilast (green stick). $\mathbf{d} \mid$ Ribbon diagram of PDE4D2 bound to roflumilast. ' $H$ ' represents the helical loops in the catalytic core. See REFS 15,16,36,40 for more information. 


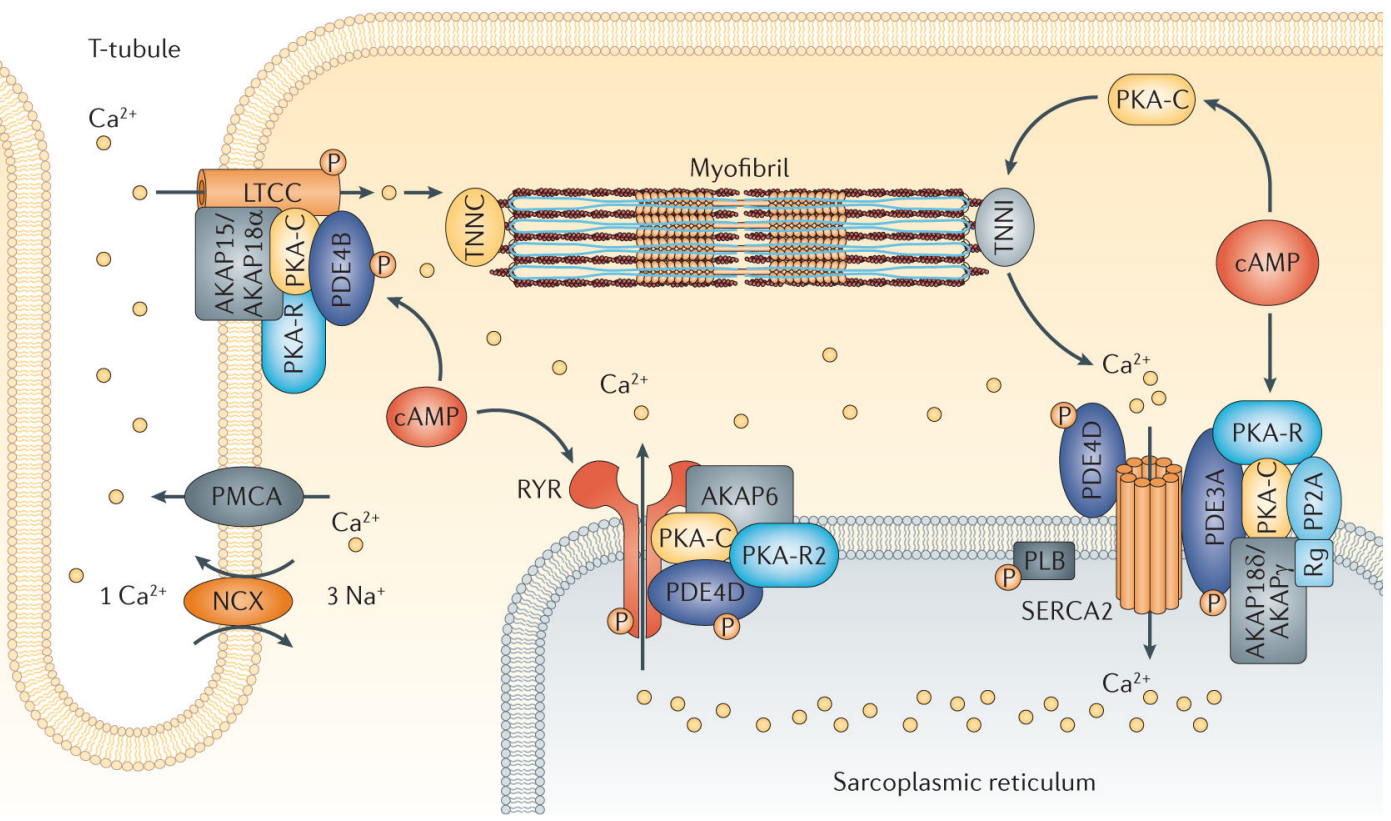

Figure 3. PDE-containing signalosomes couple cAMP-PKA signalling to myocardial contractility Phosphodiesterase 4B (PDE4B), as a component of an A-kinase anchor protein 15/18 (AKAP15/AKAP18a)-based signalosome in the cardiac L-type calcium channel (LTCC) complex, regulates the calcium current and protects against ventricular arrythmias in mice $^{167}$. AKAP6 (also known as mAKAP) serves as a scaffold for a PDE4D3-containing signalosome that is involved in regulating the release of calcium from the sarcoplasmic reticulum via the ryanodine receptor channel ${ }^{168}$. PDE3A, as a component of a sarcoplasmic/ endoplasmic reticulum calcium ATPase (SERCA) AKAP18 $\delta$-containing signalosome, is an important regulator of the effects of cAMP on calcium uptake into the sarcoplasmic reticulum ${ }^{169}$. NCX, sodium/calcium exchanger; PKA, protein kinase A; PKA-C, PKA catalytic domain; PKA-R, PKA regulatory domain; PLB, phospholamban; PMCA, plasma membrane calcium-transporting ATPase; PP2A, protein phosphatase 2A; Rg, PP2A regulatory subunit; TNNC, troponin $\mathrm{C}$; TNNI, troponin I. 


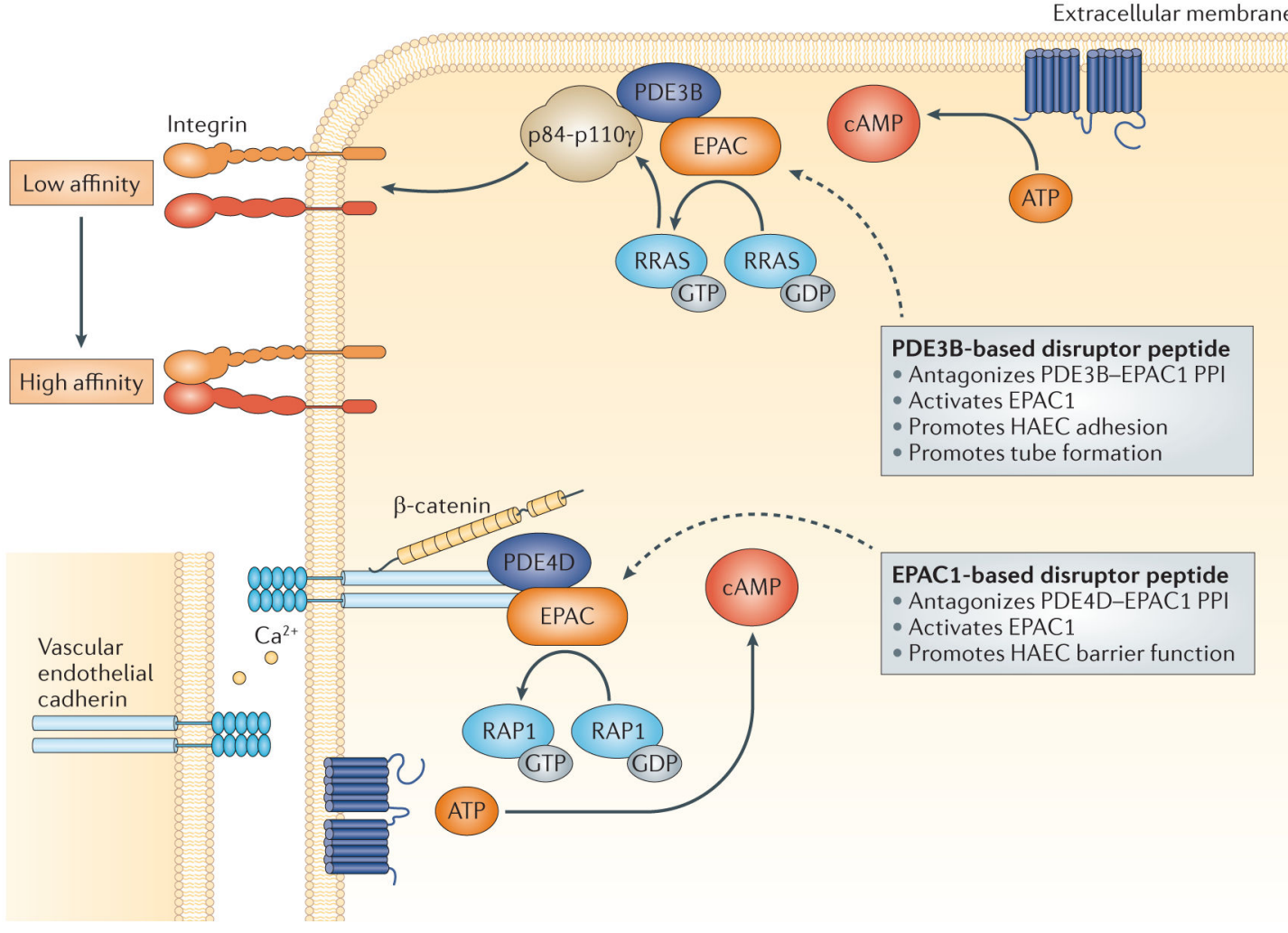

Figure 4. Human arterial endothelial cells construct two distinct PDE- and EPAC-based signalosomes to regulate, spatially and functionally, integrin- and vascular endothelial cadherinbased adhesions, respectively

As shown in the top panel, a direct interaction between phosphodiesterase 3B (PDE3B) and exchange factor directly activated by cAMP (EPAC) promotes the formation of a plasma membrane signalosome that controls cAMP-mediated activation of RAS-related protein (RRAS) and its subsequent activation of the p84-regulatory domain-associated p110 $\gamma$ subunit of phosphoinositide 3-kinase $\gamma$ and, ultimately, integrin-based adhesions with the extracellular matrix. A PDE3B-based, EPAC1-displacing peptide antagonizes PDE3BEPAC1 protein-protein interactions (PPIs), allows localized increases in cAMP and promotes signalling through this signalosome ${ }^{62}$. As shown in the bottom panel, a direct interaction between PDE4D and EPAC1 promotes the integration of these proteins into a vascular endothelial cadherin-based signalosome that allows cAMP — acting through EPAC1-based activation of small GTPase RAS-related protein 1 (RAP1) - to regulate endothelial cell permeability. An EPAC1-based, PDE4D-displacing peptide antagonizes PDE4D-EPAC1 PPIs, interferes with the integration of these proteins into the signalosome and increases endothelial cell permeability ${ }^{63}$. HAEC, human arterial endothelial cell; PIP $_{3}$, phosphatidylinositol-(3,4,5)-trisphosphate; PKB, protein kinase B. 
a

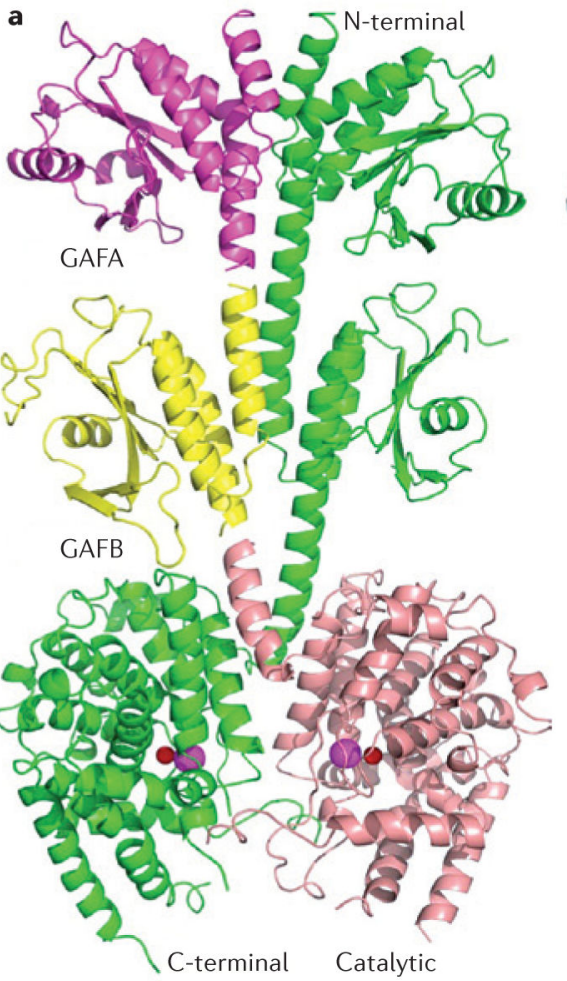

b
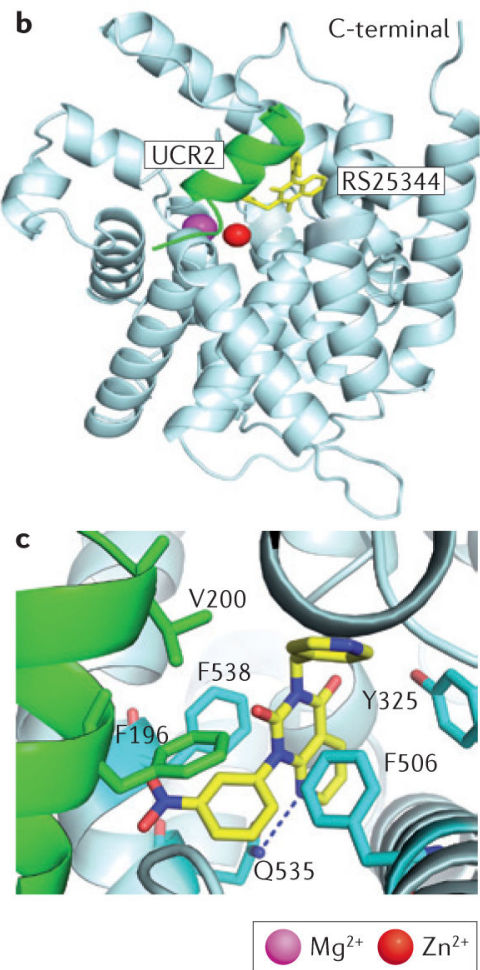

Figure 5. Allosteric modulation of PDE2 and PDE4

a Ribbon diagram of near-full-length unliganded phosphodiesterase 2A (PDE2A). The entire molecule A of the PDE2A dimer is shown in green, whereas GAF domain A (GAFA) is shown in magenta, GAFB in yellow and the catalytic domain of molecule $B$ in pale pink $^{18,164}$. b | Ribbon diagram of the PDE4 catalytic domain (shown in pale cyan) with an upstream conserved region 2 (UCR2) fragment (shown in green). The PDE4-selective inhibitor RS25344 (shown in yellow) binds to the active site of PDE4 and also interacts with the UCR2 fragment. c | Detailed view of the interaction of RS25344 (shown in yellow) with PDE4D3 residues (shown in cyan and green; Protein Data Bank ID: 3G4G). Similar to other PDE4 inhibitors, the allosteric modulator RS25344 forms a conserved hydrogen bond with the invariant Gln535 and stacks against Phe538 in the catalytic pocket. However, RS25344 makes unique hydrophobic contacts with Phe196 and Val200 in the UCR2 helix, which 'caps' and interacts with the active site ${ }^{35,163}$. 


\section{Table 1}

PDE tissue expression and impact of knockout in mice

\begin{tabular}{|c|c|c|}
\hline PDE family or gene & Tissue expression & Knockout mouse phenotypes \\
\hline $\begin{array}{l}\text { PDE1 (calcium/calmodulin- } \\
\text { activated): } \\
\text { PDE1A (nine variants), } \\
\text { PDE1B (two variants), PDE1C } \\
\text { (five variants) }\end{array}$ & $\begin{array}{l}\text { Broad; significant in cardiac and vascular } \\
\text { myocytes, central and peripheral neurons, } \\
\text { lymphoid (T and B cells) and myeloid cells } \\
\text { (macrophages have higher expression levels } \\
\text { than monocytes) as well as in testes and } \\
\text { sperm }^{1-3}\end{array}$ & $\begin{array}{l}\text { PDE1B: increased exploratory behaviour, } \\
\text { learning deficits, hyperactivity }{ }^{174} \\
\text { - } \\
\text { PDE1C: regulation of olfaction }{ }^{175}\end{array}$ \\
\hline $\begin{array}{l}\text { PDE2 (cGMP-activated): } \\
\text { PDE2A (four variants) }\end{array}$ & $\begin{array}{l}\text { Broad; significant in the brain, heart } \\
\text { (myocytes), liver, adrenal cortex, } \\
\text { endothelium and platelets }{ }^{1-3,46}\end{array}$ & - $\quad$ PDE2A: embryonic death (E17) \\
\hline $\begin{array}{l}\text { PDE3 (cGMP-inhibited): } \\
\text { PDE3A (three variants), } \\
\text { PDE3B (one variant) }\end{array}$ & $\begin{array}{l}\text { Broad; significant in cardiac and vascular } \\
\text { myocytes, brain, liver, adipose tissues, } \\
\text { pancreatic } \beta \text {-cells, endothelium, epithelium, } \\
\text { oocytes and platelets }^{1-3,46,66-67}\end{array}$ & $\begin{array}{l}\text { PDE3A: female infertility owing to oocyte } \\
\text { meiosis arrest }{ }^{67} ; \text { dysregulated vascular myocyte } \\
\text { proliferation }{ }^{121} \\
\text { - } \\
\text { PDE3B: white adipose tissue acquires brown } \\
\text { adipose tissue characteristics }{ }^{176}\end{array}$ \\
\hline $\begin{array}{l}\text { PDE4 (cAMP-specific): } \\
\text { PDE4A (seven variants), } \\
\text { PDE4B (four variants), PDE4C } \\
\text { (seven variants), PDE4D (nine } \\
\text { variants) }\end{array}$ & $\begin{array}{l}\text { Broad; significant in cells of the } \\
\text { cardiovascular, neural, immune and } \\
\text { inflammatory systems }{ }^{1-3,46}\end{array}$ & $\begin{array}{l}\text { - } \\
\text { - } \\
\text { - } \\
\text { - } \\
\text { PDE4E4C: none published } \\
\text { PDE4D: delayed growth, impaired ovulation, } \\
\text { reduced postnatal viability and refractory to } \\
\text { muscarinic cholinergic stimulation }\end{array}$ \\
\hline $\begin{array}{l}\text { PDE5 (cGMP-activated and } \\
\text { cGMP-specific): } \\
\text { PDE5A (three variants) }\end{array}$ & $\begin{array}{l}\text { Broad; significant in vascular myocytes, } \\
\text { diseased cardiac myocytes, lung, brain, } \\
\text { platelets, kidney, gastrointestinal tissues and } \\
\text { penis }{ }^{1-3,46}\end{array}$ & - $\quad$ None published \\
\hline $\begin{array}{l}\text { PDE6 (cGMP-activated and } \\
\text { cGMP-specific): } \\
\text { PDE6A (one variant), PDE6B } \\
\text { (one variant), PDE6C (one } \\
\text { variant) }\end{array}$ & $\begin{array}{l}\text { Expression limited to photoreceptors and } \\
\text { pineal gland }{ }^{1-3,46}\end{array}$ & - $\quad$ None published \\
\hline $\begin{array}{l}\text { PDE7 (cAMP-specific, } \\
\text { rolipram-insensitive): } \\
\text { PDE7A (three variants), } \\
\text { PDE7B (four variants) }\end{array}$ & $\begin{array}{l}\text { Broad in tissues including spleen, brain, } \\
\text { lung and kidney as well as in lymphoid and } \\
\text { myeloid cells }{ }^{1-3,46}\end{array}$ & $\begin{array}{l}\text { PDE7A: normal T cell activation; elevated } \\
\text { antibody response to a T cell-dependent } \\
\text { antigen } 178 \\
\text { - } \quad \text { PDE7B: none published }\end{array}$ \\
\hline $\begin{array}{l}\text { PDE8 (cAMP-specific, } \\
\text { rolipram/IBMX-insensitive): } \\
\text { PDE8A (five variants), PDE8B } \\
\text { (six variants) }\end{array}$ & $\begin{array}{l}\text { Broad; significant in testes (PDE8A) and } \\
\text { thyroid (PDE8B) }\end{array}$ & $\begin{array}{l}\text { PDE8A: increased Leydig testosterone release; } \\
\text { increased sensitivity to luteinizing hormone } \\
\text { regulation of excitation-contraction coupling and } \\
\text { calcium transients in cardiomyocytes }{ }^{179} \\
\text { - } \\
\text { PDE8B: enhanced memory and age-related } \\
\text { decline in motor performance }\end{array}$ \\
\hline $\begin{array}{l}\text { PDE9 (cAMP-specific, IBMX- } \\
\text { insensitive): } \\
\text { PDE9A ( } 20 \text { variants) }\end{array}$ & $\begin{array}{l}\text { Broad; significant in spleen, brain and } \\
\text { intestinal cells }{ }^{1-3,46}\end{array}$ & $\begin{array}{l}\text { PDE9A: on high-fat diet, knockout mice } \\
\text { demonstrated reduced insulin resistance, reduced } \\
\text { weight gain and lower fat mass }{ }^{181} \text {; PDE9A } \\
\text { deletion or inhibition increases CNS cGMP in } \\
\text { vivo }{ }^{182}\end{array}$ \\
\hline $\begin{array}{l}\text { PDE10 (cAMP-inhibited): } \\
\text { PDE10A (six variants) }\end{array}$ & $\begin{array}{l}\text { Expression limited to brain and } \\
\text { testes }^{1-3,46,183}\end{array}$ & $\begin{array}{l}\text { PDE10A: decreased exploratory behaviour, } \\
\text { hypoactivity, delayed acquisition of conditioned } \\
\text { avoidance behaviour; female PDE10A-null mice } \\
\text { are smaller }{ }^{184}\end{array}$ \\
\hline
\end{tabular}




\begin{tabular}{|c|c|c|}
\hline PDE family or gene & Tissue expression & Knockout mouse phenotypes \\
\hline $\begin{array}{l}\text { PDE11 (cGMP-activated; four } \\
\text { variants) }\end{array}$ & $\begin{array}{l}\text { Expression limited to prostate, testes and } \\
\text { salivary and pituitary gland }{ }^{1-3,46,185}\end{array}$ & $\begin{array}{l}\text { - PDE11A: enlarged lateral ventricles; abnormal } \\
\text { behaviour }\end{array}$ \\
\hline
\end{tabular}

CNS, central nervous system; E17, embryonic day 17; IBMX, isobutyl-1-methylxanthine; LPA, lysophosphatidic acid; PDE, phosphodiesterase; TNF, tumour necrosis factor. 
Table 2

Selective inhibitors of PDEs

\begin{tabular}{|c|c|c|c|}
\hline Selective inhibitor & $\mathrm{IC}_{\mathbf{5 0}}(\mathrm{nM})$ & Physiology & Potential therapeutic applications \\
\hline \multicolumn{4}{|l|}{ PDE1 } \\
\hline IC224 (ICOS) ${ }^{*}$ & 80 & \multirow{4}{*}{$\begin{array}{l}\text { - } \begin{array}{l}\text { Cardiac and vascular myocyte } \\
\text { contractility and } \\
\text { proliferation }\end{array}{ }^{105,106,187,188} \\
\text { - } \\
\begin{array}{l}\text { Monocyte and macrophage } \\
\text { differentiation }{ }^{189}\end{array} \\
\text { - } \\
\text { Acrosomal reaction }\end{array}$} & \multirow{4}{*}{$\begin{array}{ll}\text { - } & \begin{array}{l}\text { Heart failure, hypertension and } \\
\text { nitrate tolerance }\end{array}{ }^{105,106,187,188} \\
\text { - } & \text { Inflammation }{ }^{189} \\
\text { - } & \text { Fertility }{ }^{190} \\
\text { - } & \text { Parkinson's disease } \\
\end{array}$} \\
\hline IC86340: PDE1A & 440 & & \\
\hline IC86340: PDE1B & 210 & & \\
\hline IC86340: PDE1C & 60 & & \\
\hline \multicolumn{4}{|l|}{ PDE2 } \\
\hline EHNA & 800 & \multirow{5}{*}{$\begin{array}{ll}\text { - } & \begin{array}{l}\text { Natriuretic peptide inhibition of } \\
\text { ACTH-induced aldosterone }\end{array} \\
\text { secretion } & \\
\text { - } & \text { Endothelium permeability }{ }^{193,194} \\
\text { - } & \text { Platelet aggregation }{ }^{195} \\
\text { - } & \text { NMDA receptor-induced LTP }{ }^{196} \\
\text { - } & \beta_{3} \text {-adrenergic receptor-, nitric } \\
\text { oxide-dependent cardiac } \\
\text { contractility }\end{array}$} & \multirow{5}{*}{$\begin{array}{ll}\text { - } & \text { Natriuresis }{ }^{192} \\
\text { - } & \text { Atherosclerosis, inflammation, } \\
\text { sepsis }{ }^{193,194} \\
\text { - } & \text { Thrombosis }{ }^{195} \\
\text { - } & \text { Cognition and learning }{ }^{196} \\
\text { - } & \text { Heart failure } \\
\text { 59 }\end{array}$} \\
\hline Oxidole & 40 & & \\
\hline BAY60-7550 (Bayer) & 4.7 & & \\
\hline PDP (Bayer) & 0.6 & & \\
\hline IC933 (ICOS) & 4 & & \\
\hline \multicolumn{4}{|l|}{ PDE3 } \\
\hline Cilostamide & $25-50$ & \multirow{5}{*}{ 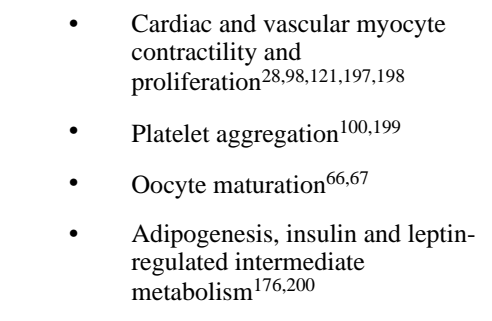 } & \multirow{5}{*}{$\begin{array}{ll}\text { - } & \begin{array}{l}\text { Heart failure, } \\
\text { hypertension }\end{array} \\
\text { - } & \text { Thrombosis }^{199} \\
\text { - } & \text { Fertility } \\
\text { - } & \text { Obesititity and satiety } \\
\end{array}$} \\
\hline Enoximone & $10 \times 10^{3}$ & & \\
\hline Milrinone & 150 & & \\
\hline Cilostazol (Otsuka) & 200 & & \\
\hline OPC-33540 (Otsuka) & 0.3 & & \\
\hline \multicolumn{4}{|l|}{ PDE4 } \\
\hline Rolipram & 1,000 & \multirow{8}{*}{ 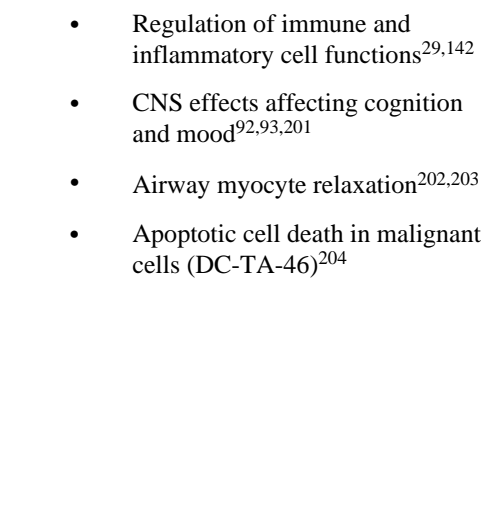 } & - Inflammation ${ }^{29,142}$ \\
\hline Cilomilast (GSK) & $70-120$ & & - Depression, anxiety, cognition \\
\hline Roflumilast (Altana) & 0.6 & & disease and Parkinson's \\
\hline GSK256066 $(\mathrm{GSK})$ & 0.0032 & & disease ${ }^{92,93,201,201}$ \\
\hline AWD 12-281 (Elbion/GSK) & 10 & & and COPD $202,203,205,206$ \\
\hline Apremilast (Celgene) & 74 & & - $\quad$ IBD (tetomilast; Phase III) ${ }^{208}$ \\
\hline Quinolyl oxazole ${ }^{\ddagger}$ (Merck) & 0.06 & & 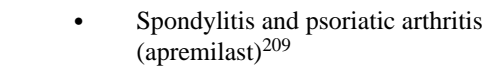 \\
\hline DC-TA-46 & 10 & & $\begin{array}{l}\text { - Inflammation (quinolyl } \\
\text { axazole) })^{210} \\
\text { - } \quad \text { Cancer }^{204}\end{array}$ \\
\hline PDE5 & & & \\
\hline
\end{tabular}




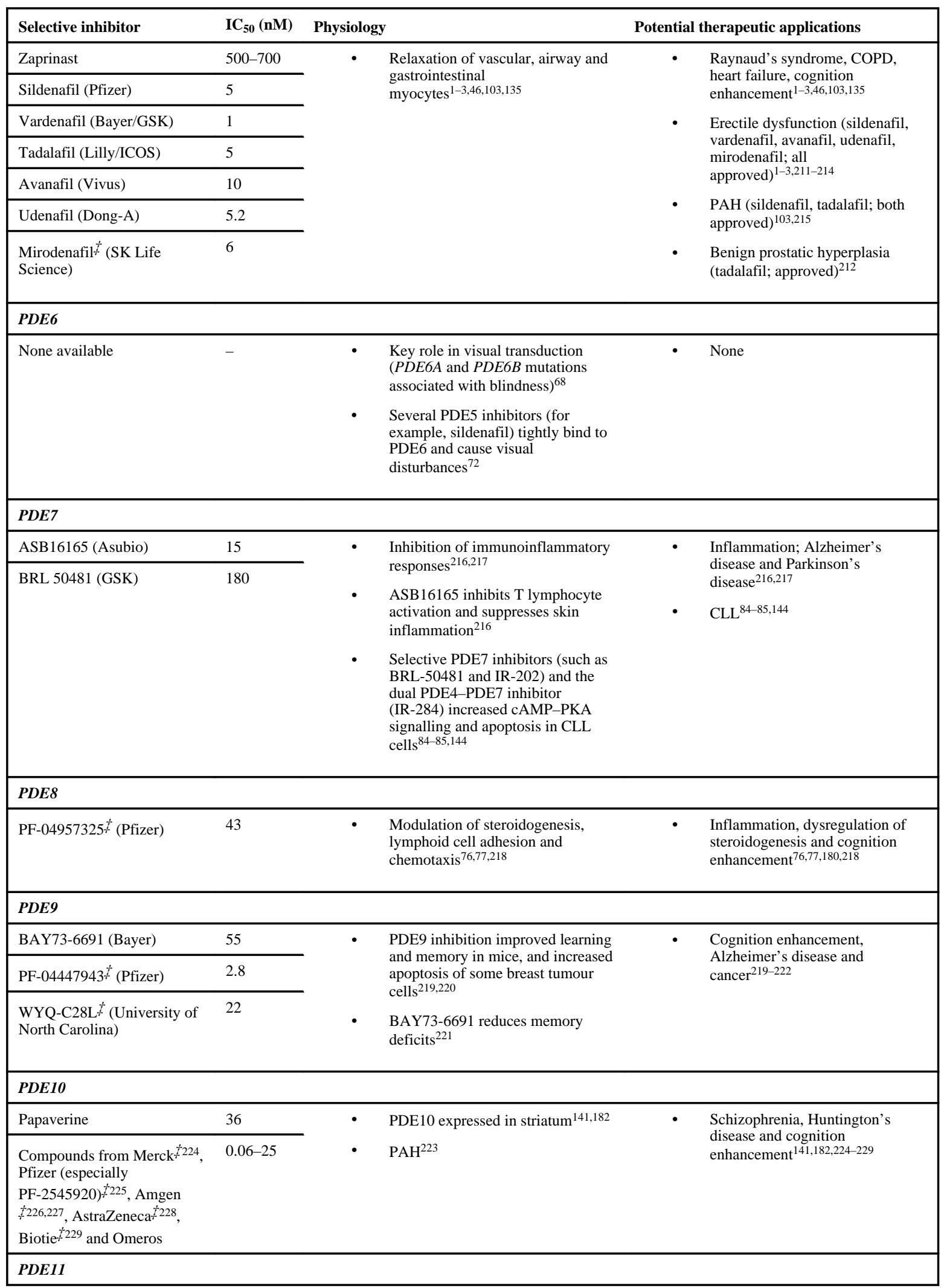




\begin{tabular}{|c|c|c|c|}
\hline Selective inhibitor & $\mathrm{IC}_{50}(\mathrm{nM})$ & Physiology & Potential therapeutic applications \\
\hline None available & - & $\begin{array}{l}\text { - } \\
\text { Inhibition of sperm motility }{ }^{230} \\
\text { PDE11A-inactivating mutations in } \\
\text { patients with Cushing disease and } \\
\text { bilateral micronodular adrenal } \\
\text { hyperplasia }{ }^{80,81} \\
\text { - } \\
\text { PDE11 gene defects and mutations } \\
\text { contribute to testicular and adrenal } \\
\text { tumours, Cushing disease and } \\
\text { psychiatric diseases }\end{array}$ & $\begin{array}{ll}\text { - } & \text { Fertility } \\
\text { - } & \text { Reduction of endocrine } \\
\text { neoplasia } & 80,81 \\
\text { - } & \text { Depression }^{231}\end{array}$ \\
\hline
\end{tabular}

ACTH, adrenocorticotropic hormone; CLL, chronic lymphocytic leukaemia, COPD, chronic obstructive pulmonary disease; CNS, central nervous system; GSK, GlaxoSmithKline; IBD, inflammatory bowel disease; LTP, long-term potentiation; NMDA, $N$-methyl-D-aspartate; PAH, pulmonary arterial hypertension; PDE, phosphodiesterase.

* The original developers of the inhibitors are indicated in parentheses; otherwise, they are commercially available.

* Structural information was used in the discovery of these inhibitors. 


\section{Table 3}

Compartmentalized PDE signalling in mammalian cells

\begin{tabular}{|c|c|c|c|c|}
\hline PDE & Subcellular compartment & Potential signalling partners & Cell function studies & Refs \\
\hline \multicolumn{5}{|l|}{ PDE1 } \\
\hline PDE1A & Perinuclear, nuclear & CaM, PKG, EPAC & Cardiac myocyte proliferation & 232 \\
\hline PDE1C & Lysosome & CaM, CNGC, soluble adenylyl cyclase & Myocyte collagen degradation & 233 \\
\hline \multicolumn{5}{|l|}{ PDE2 } \\
\hline PDE2A & Mitochondria & $\begin{array}{l}\text { Soluble adenylyl cyclase (not tested } \\
\text { directly) }\end{array}$ & Respiration & 234 \\
\hline PDE2A & Plasma membrane & Synaptophysin (not tested directly) & Synaptic functions & 235 \\
\hline PDE2A & Plasma membrane & $\begin{array}{l}\text { PMCA4, nNOS, PKA-R2, RYR, L-type } \\
\text { calcium channels, PKG (not tested directly) }\end{array}$ & Cardiac contractility & 236 \\
\hline PDE2A & Plasma membrane & $\begin{array}{l}\text { Particulate GC, PKA-R2, AKAP (not } \\
\text { tested directly) }\end{array}$ & Cardiac contractility & 237 \\
\hline \multicolumn{5}{|l|}{ PDE3 } \\
\hline PDE3A & Plasma membrane & PKA-R2-AKAP (not tested directly) & Cardiac contractility & 58 \\
\hline PDE3A & Plasma membrane & $\begin{array}{l}\text { TRPC3, TRPC6, PKA-R2 (not tested } \\
\text { directly) }\end{array}$ & Vascular myocyte contractility & 238 \\
\hline PDE3A & ER & $\begin{array}{l}\text { SERCA2A, PLB, AKAP18 } 8, \text { PKA-R2, } \\
\text { PP2A }\end{array}$ & Cardiac myocyte contractility & 169 \\
\hline PDE3A & Intracellular membranes & BIG1, BIG2, PKA-R1 & Vesicular transport & 239 \\
\hline PDE3A & Plasma membrane & CFTR & Epithelial electrical potential & 240 \\
\hline PDE3A & Plasma membrane, cytoplasm & $14-3-3$ & Platelet aggregation & 241 \\
\hline PDE3B & Plasma membrane, cytoplasm & 14-3-3ß, PKA-R2, PKB & PDE3B inactivation & 242 \\
\hline PDE3B & $\begin{array}{l}\text { Insulin granules, plasma } \\
\text { membrane, ER }\end{array}$ & p85, PP2A, PKB, HSP90, IRS1, 14-3-3 & Insulin-mediated lipolysis & 243 \\
\hline PDE3B & Plasma membrane & EPAC1, p84-p110 $\gamma$, RRAS & Endothelial cell migration & 62 \\
\hline PDE3B & Plasma membrane & $\mathrm{p} 110 \gamma, \mathrm{PKA}-\mathrm{R} 2$ & Cardiac myocyte contractility & 244 \\
\hline \multicolumn{5}{|l|}{ PDE4 } \\
\hline PDE4A & Plasma membrane & p75NTR & Regulated PAI1 expression & 245 \\
\hline PDE4A & Cytoplasm & SQSTM1 & N/A & 246 \\
\hline PDE4A1 & Cytoplasm, Golgi & Phosphatidic acid-rich membranes & N/A & 247 \\
\hline PDE4A5 & Plasma membrane & AKAP3 & Sperm motility & 248 \\
\hline PDE4A & Nuclear, mitochondria & AKAP95, AKAP149, MTG & $\mathrm{T}$ cell-regulated inflammation & 249 \\
\hline PDE4A & Plasma membrane, cytoplasm & LYN & N/A & 250 \\
\hline PDE4A5 & Plasma membrane, cytoplasm & Immunophilin AIP & N/A & 251 \\
\hline PDE4B & Mitochondria, centrosome & $\begin{array}{l}\text { DISC1, PDE4D, NDEL1, NDE1, } \\
\text { PAFAH1B1, tubulin, dynein, ATF4 }\end{array}$ & Neural electrical potential & 252,253 \\
\hline PDE4C & Plasma membrane & $\begin{array}{l}\text { ADCY5, ADCY6, AKAP150, PKA-R2, } \\
\text { polystin } 2\end{array}$ & $\begin{array}{l}\text { Renal tubule electrical } \\
\text { potential }\end{array}$ & 254 \\
\hline PDE4D & Cytoplasm & $\beta$-arrestin & Cardiac function & 255 \\
\hline PDE4D & SR & RHEB, mTOR & Protein synthesis & 256 \\
\hline PDE4D & Golgi & Myomegalin, PKA-R2 & Cardiac myocyte contractility & 257 \\
\hline
\end{tabular}




\begin{tabular}{|c|c|c|c|c|}
\hline PDE & Subcellular compartment & Potential signalling partners & Cell function studies & Refs \\
\hline PDE4D & SR & SERCA & Cardiac myocyte contractility & 258 \\
\hline PDE4D & Proteosome & PHD2 & Protein degradation & 259 \\
\hline PDE4D3 & Plasma membrane & AKAP18 8, AQP2 & Water resorption & 260 \\
\hline PDE4D3 & Nuclear & AKAP6, PKA-R2, PP2A, ERK5, EPAC1 & Cardiac contractility & 61,261 \\
\hline PDE4D3 & ER & RYR2, PKA-R2 & Heart failure and arrhythmias & 168 \\
\hline PDE4D3 & Centrosome & AKAP9, PKA-R2 (not tested directly) & Cell division & 64 \\
\hline PDE4D3 & Plasma membrane & RXFP1, $\beta$-arrestin, AKAP79 & Relaxin-mediated signalling & 262 \\
\hline PDE4D3 & Plasma membrane & KCNQ1, KCNE1, AKAP9, PKA-R2, PP1 & Cardiac myocyte contraction & 263 \\
\hline PDE4D3, PDE4D8, PDE4D9 & Plasma membrane, cytoplasm & AKAP5, AKAP12 & Vascular myocyte migration & 264 \\
\hline PDE4D4 & Plasma membrane & Spectrin & Endothelial permeability & 265 \\
\hline PDE4D4 & Plasma membrane, cytoplasm & SRC, LYN, FYN kinase (SH3 domains) & Signalling & 266 \\
\hline PDE4D5 & Plasma membrane & FAK, RACK1 & Cell polarity and migration & 157,159 \\
\hline PDE4D5, PDE4D7 & Plasma membrane & $\begin{array}{l}\text { EPAC1, vascular endothelial cadherin, } \beta \text { - } \\
\text { catenin, p120-catenin, PKA-R2 }\end{array}$ & Endothelial permeability & 63 \\
\hline PDE4D5, PDE4D8, PDE4D9 & Plasma membrane & $\beta_{2}$-adrenergic receptors, AKAP79, $\beta$-arrestin & Cardiac myocyte contractility & 267,268 \\
\hline \multicolumn{5}{|l|}{ PDE5 } \\
\hline PDE5A & Plasma membrane & PKG (not tested directly) & Cardiac myocyte contractility & 269 \\
\hline PDE5A & ER & PKG1 $\beta$, IRAG, $\mathrm{InsP}_{3}$ receptor 1 & Platelet aggregation & 270 \\
\hline PDE5A & Cytoplasm & PKA-R2, $\mathrm{AKAP}_{\text {Unk }}$ (not tested directly) & Cardiac contractility & 237 \\
\hline \multicolumn{5}{|l|}{ PDE7 } \\
\hline PDE7A & Golgi & MTG & Inhibition of $\mathrm{T}$ cell activation & 249 \\
\hline PDE7A & Golgi, centrosome & PKA catalytic domain & Signalling & 271 \\
\hline \multicolumn{5}{|l|}{ PDE 8} \\
\hline PDE8A & Mitochondria & $\mathrm{I} \kappa \mathrm{B} \beta, \mathrm{p} 105, \mathrm{p} 100$ & Signalling & 272 \\
\hline PDE8A & Cytoplasm & RAF1 & Signalling & 65 \\
\hline
\end{tabular}

14-3-3, 14-3-3 protein (YWHAQ); ADCY5, adenylyl cyclase 5; AIP, aryl hydrocarbon receptor interacting protein (also known as XAP2); AKAP, A-kinase anchor protein; AQP, aquaporin; ATF4, activating transcription factor 4; BIG, Brefeldin A-inhibited guanine nucleotide exchange protein; CaM, calmodulin; CFTR, cystic fibrosis transmembrane conductance regulator; CNGC, cyclic nucleotide gated ion channel; DISC1, disrupted in schizophrenia homolog 1; EPAC, exchange factor directly activated by cAMP; ER, endoplasmic reticulum; ERK5, extracellular

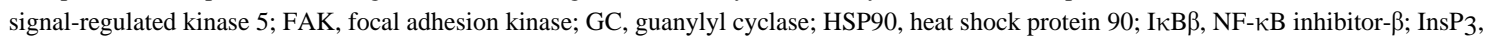
inositol-1,4,5-trisphosphate; IRAG, inositol 1,4,5-trisphosphate-associated cGMP kinase substrate; IRS1, insulin receptor substrate 1; KCNE1, potassium voltage-gated channel subfamily E member 1; KCNQ1, potassium voltage-gated channel, KQT-like subfamily, member 1; LYN, LCK/ YES-related novel protein tyrosine kinase; MTG, myeloid translocation gene; mTOR, mammalian target of rapamycin; N/A, not available; NDE1, nudE neurodevelopment protein 1; NDEL1, NDE1-like protein 1; nNOS, neuronal nitric oxide synthase; p75NTR, p75 neurotrophin receptor; PAFAH1B1, platelet-activating factor acetylhydrolase IB subunit-alpha; PAI1, plasminogen activator inhibitor 1; PDE, phosphodiesterase; PHD2, prolyl hydroxylase domain protein 2; PKA, protein kinase A; PKA-R, PKA regulatory domain; PLB, phospholamban; PMCA4, plasma membrane calcium-transporting ATPase 4; PP, protein phosphatase; RACK1, receptor of activated protein kinase C1; RHEB, RAS homolog enriched in brain; RRAS, RAS-related protein; RXFP1, relaxin family peptide receptor 1; RYR, ryanodine receptor; SERCA, sarcoplasmic/endoplasmic reticulum calcium ATPase 2; SQSTM1, sequestosome 1; SR, sarcoplasmic reticulum; TRPC, transient receptor potential channel. Detailed information concerning interacting proteins and methods used to assess these interactions is included in Supplementary information S3 (table). 
Table 4

PDE inhibitors currently under clinical study

\begin{tabular}{|c|c|c|c|}
\hline Agents (sponsors) & Indication & Status & ClinicalTrials.gov identifiers \\
\hline \multicolumn{4}{|l|}{ Pan-PDE } \\
\hline Resveratrol (US National Institute on Aging) & Alzheimer's disease & Phase II & NCT01504854 \\
\hline Resveratrol (American Diabetes Association) & Impaired glucose tolerance & Phase II & NCT01375959 \\
\hline \multicolumn{4}{|l|}{ PDE1 } \\
\hline ITI-214 (Takeda/Intra-Cellular Therapies) & Schizophrenia & Phase I & NCT01900522 \\
\hline \multicolumn{4}{|l|}{ PDE2 } \\
\hline PF-05180999 (Pfizer) & Migraine & Phase I & NCT01981486 \\
\hline \multicolumn{4}{|l|}{ PDE3 } \\
\hline Cilostazol (Universitair Ziekenhuis Brussel) & Fertility & Unknown & NCT00823420 \\
\hline Cilostazol (Korea Otsuka Pharmaceutical) & Chronic tinnitus & Phase II & NCT01378650 \\
\hline Cilostazol (Seoul National University Hospital) & Dementia & Phase IV & NCT01409564 \\
\hline Cilostazol (Hanyang University) & Atherosclerotic events & Phase IV & NCT00886574 \\
\hline Cilostazol (University of Southern California) & Fertility & Phase II & NCT01915069 \\
\hline Cilostazol (Kobe City General Hospital) & Restenosis & Phase IV & NCT01261234 \\
\hline Cilostazol (Korea Otsuka Pharmaceutical) & Ischaemic stroke & Phase IV & NCT01013532 \\
\hline $\begin{array}{l}\text { Milrinone (University of Nebraska/Thoratec } \\
\text { Corporation) }\end{array}$ & Heart failure & Phase I & NCT01571037 \\
\hline Enoximone (Gilead Sciences/AstraZeneca) & Heart failure & Phase III & NCT00077948 \\
\hline \multicolumn{4}{|l|}{ PDE4 } \\
\hline Rolipram (US National Institutes of Health) & Depression & Phase I & NCT00369798 \\
\hline Rolipram (GlaxoSmithKline) & Huntington's disease & Phase I & NCT01602900 \\
\hline GSK356278 (GlaxoSmithKline) & Huntington's disease & Phase I & NCT01602900 \\
\hline ASP9831 (Astellas Pharma) & Non-alcoholic steatohepatitis & Phase II & NCT00668070 \\
\hline GSK256066 (GlaxoSmithKline) & Rhinitis & Phase II & NCT00464568 \\
\hline CHF6001 (Chiesi Farmaceutici) & Asthma; COPD & Phase II & NCT01730404 \\
\hline Apremilast (Celgene) & Ankylosing spondyloarthritis & Phase III & NCT01583374 \\
\hline Apremilast (Celgene) & Acne & Phase II & NCT01074502 \\
\hline MK0952 (Merck Sharp \& Dohme) & Alzheimer's disease & Phase II & NCT00362024 \\
\hline CHF6001 (Chiesi Farmaceutici) & COPD & Phase II & NCT01730404 \\
\hline Roflumilast (Takeda) & Atopic dermatitis & Phase II & NCT01856764 \\
\hline Roflumilast (Takeda) & Dementia & Phase II & NCT01433666 \\
\hline $\begin{array}{l}\text { Roflumilast (The National Heart, Lung and Blood } \\
\text { Institute) }\end{array}$ & Obesity & Phase II & NCT01862029 \\
\hline Sildenafil (University of Milan) & Heart failure & Phase III & NCT00407446 \\
\hline Sildenafil, tadalafil (Cedars-Sinai Medical Center) & Duchenne muscular dystrophy & Phase I & NCT01580501; NCT01359670 \\
\hline Sildenafil (IRCCS, San Raffaele) & $\begin{array}{l}\text { Endocrine function in patients with } \\
\text { diabetes }\end{array}$ & Phase III & NCT00420901 \\
\hline Sildenafil (Vanderbilt University) & Impaired glucose tolerance & Phase III & NCT01812434 \\
\hline
\end{tabular}




\begin{tabular}{|c|c|c|c|}
\hline Agents (sponsors) & Indication & Status & ClinicalTrials.gov identifiers \\
\hline Sildenafil (University of Minnesota) & Cardiac vasculopathy & Phase II & NCT01812434 \\
\hline Sildenafil (Massachusetts General Hospital) & Schizophrenia & Phase IV & NCT00455715 \\
\hline Tadalafil (Västra Götaland Region) & Diabetes & Phase II & NCT01238224 \\
\hline Tadalafil (University of Roma La Sapienza) & Diabetic cardiomyopathy & Phase IV & NCT01803828 \\
\hline Tadalafil (Cedars-Sinai Medical Center) & Becker muscular dystrophy & Phase IV & NCT01070511 \\
\hline $\begin{array}{l}\text { Tadalafil (Sidney Kimmel Comprehensive Cancer } \\
\text { Center) }\end{array}$ & Multiple myeloma & Phase II & NCT01374217 \\
\hline Tadalafil (Washington University School of Medicine) & Aortic stenosis & Phase IV & NCT01275339 \\
\hline $\begin{array}{l}\text { Tadalafil (Sidney Kimmel Comprehensive Cancer } \\
\text { Center) }\end{array}$ & Head and neck cancer & Phase IV & NCT01697800 \\
\hline Tadalafil (Sanjay Gandhi Institute of Medical Sciences) & Lung diseases & Phase III & NCT01553981 \\
\hline Udenafil (Seoul National University Hospital) & Raynaud's phenomenon & Phase III & NCT01280266 \\
\hline PF-00489791 (Pfizer) & Diabetic nephropathy & Phase III & NCT01200394 \\
\hline PF-04447943 (Pfizer) & Alzheimer's disease & Phase II & NCT00930059 \\
\hline PF-04447943 (Pfizer) & Alzheimer's disease & Phase II & NCT00988598 \\
\hline PF-02545920 (Pfizer) & Schizophrenia & Phase I & NCT01244880 \\
\hline PF-02545920 (Pfizer) & Huntington's disease & Phase I & NCT01806896 \\
\hline RO5545965 (Hoffmann-La Roche) & Unknown & Phase I & NCT01923025 \\
\hline AMG 579 (Amgen) & Schizophrenia & Phase I & NCT01568203 \\
\hline TAK- 063 (Takeda) & Schizophrenia & Phase I & NCT01879722 \\
\hline AN2898 and AN2728 (Anacor Pharmaceuticals) & Atopic dermatitis & Phase II & NCT01301508 \\
\hline
\end{tabular}

COPD, chronic obstructive pulmonary disease; IRCCS, L'Istituto di Ricovero e Cura a Carattere Scientifico; PDE, phosphodiesterase. 